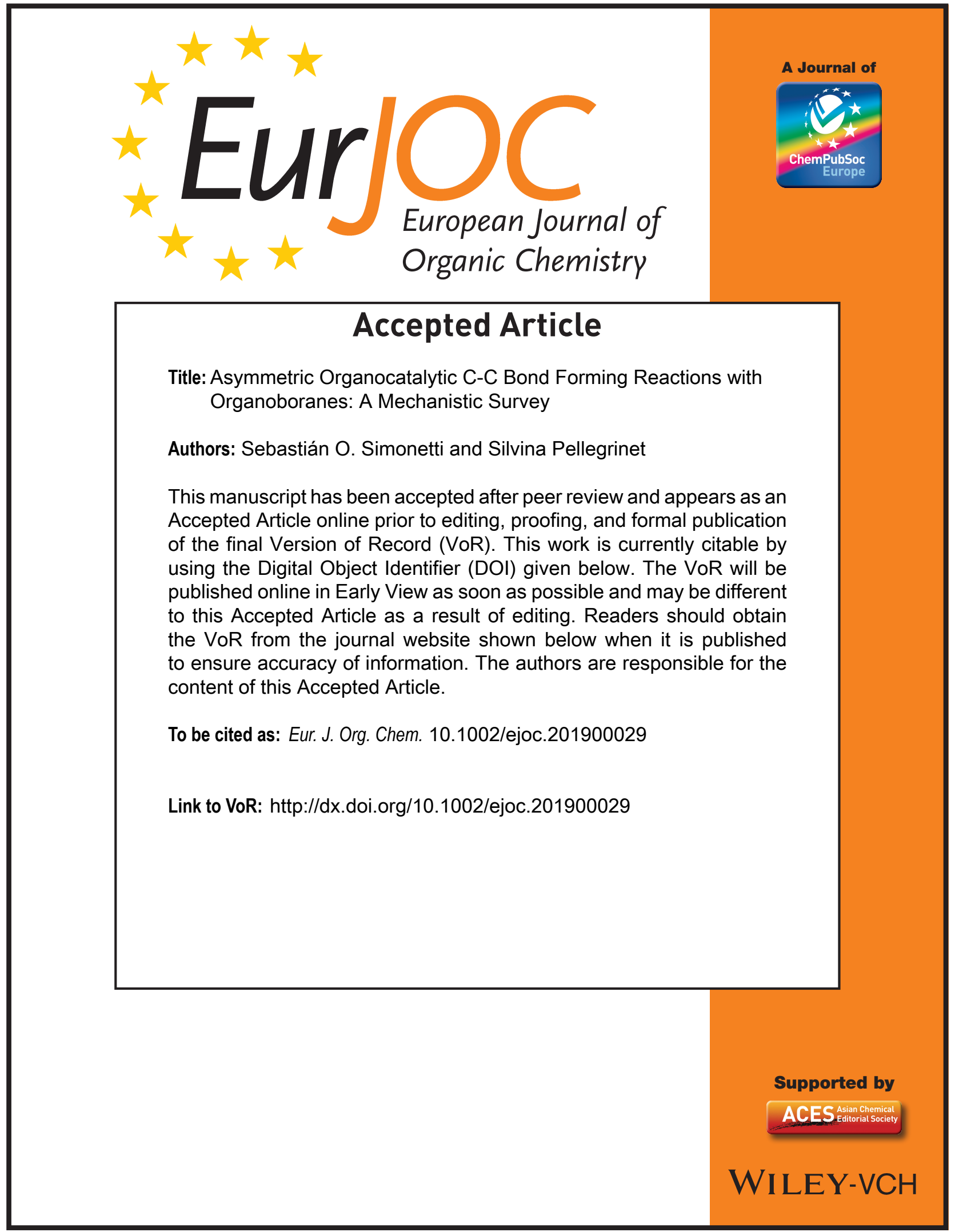




\title{
Asymmetric Organocatalytic C-C Bond Forming Reactions with Organoboron Compounds: A Mechanistic Survey
}

\author{
Sebastián O. Simonetti, ${ }^{[a]}$ and Silvina C. Pellegrinet ${ }^{\star[a]}$ \\ Dedicated to the memory of Prof. Dr. Edmundo A. Rúveda
}

\begin{abstract}
The recent development of asymmetric organocatalytic C$\mathrm{C}$ bond forming reactions involving organoboranes has attracted big interest in the synthetic community. Asymmetric organocatalytic additions to enones, aldehydes, ketones, imines, dienes and related systems can be carried out with different organoboron compounds (boronic acids and esters and trifluoroborate salts) to give products with very good yields and enantiomeric ratios. In particular, many BINOL and $\alpha$-hydroxyacid derivatives have been used as chiral organocatalysts. In this review, we describe the mechanisms that have been proposed based on theoretical and experimental studies for asymmetric organocatalytic $\mathrm{C}-\mathrm{C}$ bond forming reactions with organoboron compounds. The mechanistic understanding that has been gained should contribute to the progress of this promising area of organic chemistry.
\end{abstract}

\section{Introduction}

Organoboron compounds exhibit wide synthetic versatility and availability. ${ }^{1,2}$ The hydroboration reaction developed by Brown ${ }^{3}$ demonstrated the potential of organoboranes, providing an invaluable tool to inspire the development of further reactions. ${ }^{4}$ Boranes played a key role in the progress of many areas of modern organic chemistry. ${ }^{5}$ In addition, organoboron compounds have been used in the synthesis of new materials such as polymers and biosensors. ${ }^{6}$ Also, organoboranes can be synthetized with simple approaches and smooth conditions. ${ }^{7}$ Moreover, in contrast with other sources of carbon such as organostannanes 8 and organosilicon compounds, 9 organoboronic acids and esters are stable and safe and have shown to be a useful source to form carbon-carbon bonds. ${ }^{10}$ Furthermore, the recent incorporation of trifluoroborate salts, provided further advances in terms of manipulation and robustness of the reactions. ${ }^{11}$

In addition, organoboron compounds have been widely used in asymmetric synthesis ${ }^{12}$ either as reagents ${ }^{13}$ or catalysts. ${ }^{14}$ Furthermore, asymmetric organometallic strategies

[a] Dr. S. O. Simonetti, Prof. Dr. S. C. Pellegrinet Instituto de Química Rosario (IQUIR-CONICET), Facultad de Ciencias Bioquímicas y Farmacéuticas, Universidad Nacional de Rosario, Suipacha 531, Rosario 2000, Argentina E-mail: pellegrinet@iquir-conicet.gov.ar

Supporting information for this article is given via a link at the end of the document. based on the use of organoboronic derivatives and chiral ligands have been described. ${ }^{15}$ The recent development of asymmetric organocatalytic methodologies with organoboranes completes the range of reactions where this type of compounds can be used. Scheme 1 shows the general sketch for organocatalytic activation of boron reagents, together with the typical transformations in which this strategy has been applied (Eq. 1 and 2). In 2005, Wu and Chong reported the first asymmetric organocatalytic $\mathrm{C}-\mathrm{C}$ bond forming reaction, which introduced an alkynyl moiety in the $\beta$ position of an $\alpha, \beta$-unsaturated ketone. ${ }^{16}$ Based on general concepts of organocatalysis, ${ }^{17}$ they proposed that the starting achiral boronate $\boldsymbol{i}$ should contain two labile groups attached to the boron atom to allow transesterification with the chiral organocatalyst ii to give the chiral species iii (Scheme 2). Then, iii should react with the substrate (iv) faster than $\boldsymbol{i}$, to form the $\mathrm{C}-\mathrm{C}$ bond enantioselectively, affording product v. Ultimately, exchange of ligands would give the final product $\boldsymbol{v i}$ and simultaneously release the chiral organocatalyst $i$. This paradigm allowed the development of numerous and efficient organocatalytic asymmetric strategies to form C-C bonds using organoboron compounds as synthons.

Recent reviews address this topic in great detail from the synthetic point of view ${ }^{18}$ or either focus on a particular type of reaction ${ }^{19}$ or catalyst. ${ }^{20}$ Mainly, the asymmetric organocatalytic reactions developed so far have been 1,4-additions to enones 1 to afford $\beta$-substituted ketones 2 (Eq. 1, Scheme 1) and 1,2additions to aldehydes or ketones $\mathbf{3}$ or imines $\mathbf{4}$ to generate the alcohol or amine products $\mathbf{5}$ or $\mathbf{6}$, respectively (Eq. 2, Scheme 1). Due to the great interest of these organocatalytic organoboronbased methodologies, several groups have investigated the mechanisms with theoretical and/or experimental approaches. These studies helped to better understand the catalytic cycles and also to develop new transformations and catalysts.

It is important to remark that, among the 1,2-additions, the Borono-Mannich reaction, also called Petasis reaction is of notable importance. The general mechanism of such reaction has been studied using different tools. ${ }^{21}$ Although many asymmetric organocatalytic approaches have been developed for the Petasis reaction, to our knowledge no theoretical mechanistic studies have been performed yet. Therefore, the Petasis reaction is out of the scope of this review. 


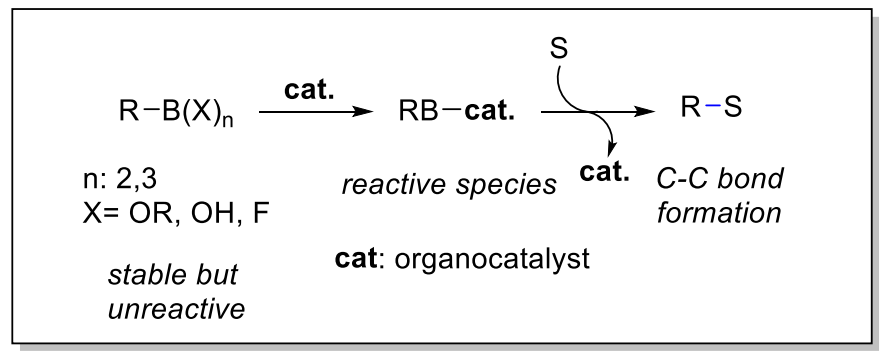

This review:

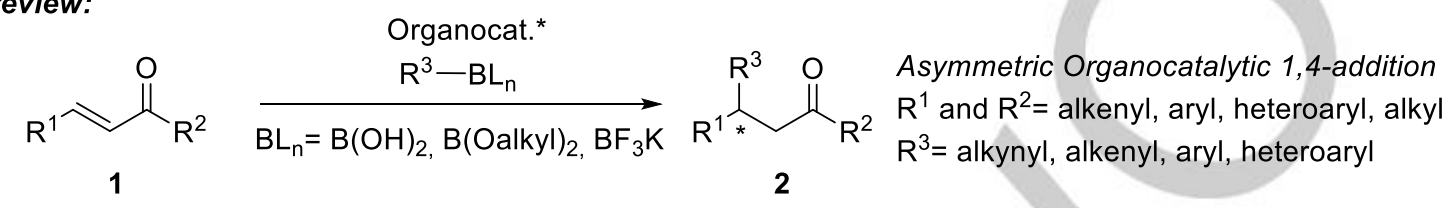<smiles>[R]C([R])=[X]</smiles>

$$
\underset{\mathrm{BL}_{\mathrm{n}}=\mathrm{B}(\mathrm{OH})_{2}, \mathrm{~B}(\text { Oalkyl })_{2}}{\longrightarrow}
$$

$3 X=0$

$4 \mathrm{X}=\mathrm{N}(\mathrm{CO}) \mathrm{R}, \mathrm{NR}$
Asymmetric Organocatalytic 1,2-addition
$\mathrm{R}^{1}$ and $\mathrm{R}^{2}=$ alkenyl, aryl, heteroaryl, alkyl

$\mathrm{R}^{3}=$ allyl, alkynyl, alkenyl, aryl, heteroaryl, allenyl
(Eq. 1)

$5 \mathrm{X}=\mathrm{OH}$

$6 \mathrm{X}=\mathrm{NH}(\mathrm{CO}) \mathrm{R}, \mathrm{NHR}$

Scheme 1. General organocatalytic reaction with organoboron compounds. Asymmetric organocatalytic reactions covered in this review (Eq. 1 and Eq. 2).

In this review, we have focused on the mechanistic aspects of asymmetric organocatalysis with organoboranes in $\mathrm{C}-\mathrm{C}$ bondforming reactions. In particular, we describe the theoretical and experimental mechanistic studies for asymmetric 1,4- and 1,2additions. The former consisted in DFT calculations, while the later comprised NMR and ESI-MS studies as well as kinetic data As a complement, in the supporting information we list further reactions that have not been theoretically investigated yet, to show the next challenges on the topic.

\section{Asymmetric Organocatalytic 1,4- Additions}

Asymmetric organocatalytic 1,4-additions to $\alpha, \beta$ unsaturated carbonyl systems are the reactions for which organocatalysis with organoboronic compounds initially had the major development. ${ }^{18 \mathrm{c}}$ The topic has evolved along with the synthesis of new chiral BINOL catalysts, mainly through the incorporation of electron withdrawing groups in C3 and C3'. While most theoretical and experimental mechanistic investigations were carried out with chiral BINOL catalysts, the mechanisms using $\alpha$-hydroxy acids also have been investigated, but to a lesser extent.

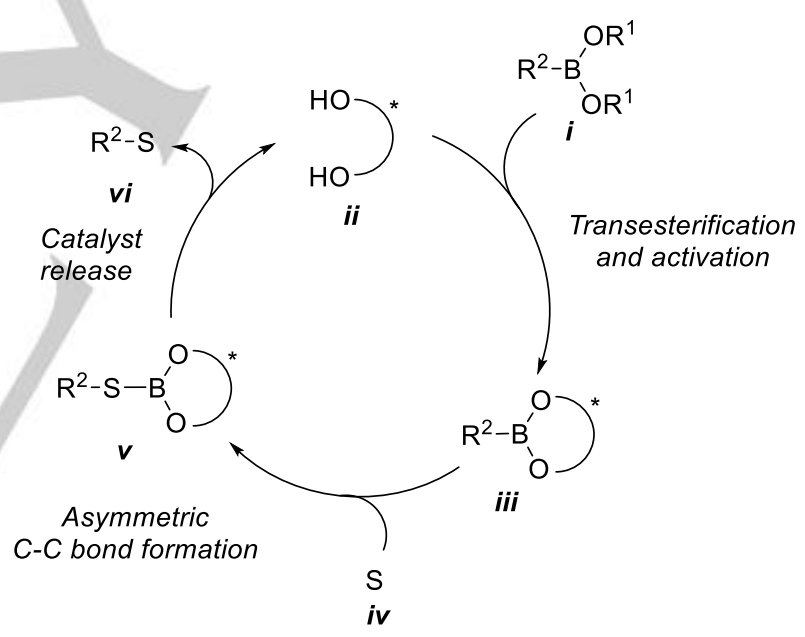

Scheme 2. General catalytic cycle of the asymmetric C-C bond formation with boronic acid and esters derivatives.

\subsection{Use of chiral BINOLs}

Chiral diols such as BINOLs are considered privileged structures in organocatalysis representing one of the most useful molecules to accelerate and induce asymmetry in a reaction. ${ }^{22}$

The seminal work that demonstrated the "proof of principle" for asymmetric organocatalytic organoboron reactions was published by $\mathrm{Wu}$ and Chong and consisted in the enantioselective 1,4-alkynylboration of enones with diisopropyl alkynylboronate esters 7 catalyzed by (S)-3,3'-diiodo-BINOL (S)$9(20 \mathrm{~mol} \%)$ (Scheme 3$).{ }^{16}$ The reaction was carried out with 3.0 equiv. of 7 under mild conditions. The $\beta$-substituted products 8 were obtained with yields from $78 \%$ to $97 \%$ and ee in the range 82 to $96 \%$. The methodology was validated with 8 examples. 
The authors proposed that the activation of the boronate species occurred by rapid transesterification with (S)-9 to afford the chiral reactive species $\mathbf{1 0}$, which attacks enone $\mathbf{1}$ forming the $\mathrm{C}$ $\mathrm{C}$ bond to give product $\mathbf{8}$ with high levels of enantioselectivity.

In 2006, Pellegrinet and Goodman published the theoretical study of this reaction, representing the first theoretical study of an asymmetric organocatalytic reaction with organoboron compounds (Scheme 4). ${ }^{23}$ The study was performed at the B3LYP/lacvp* level of theory on a model system using 3,3'-diiodo-biphenyl (S)-11 instead of the corresponding BINOL (S)-9. The computed energy gap between the transition structures derived from alkynylboronate 7 (TS18) and the reactive species 12 (TS17) was ca. $16 \mathrm{kcal} \mathrm{mol}^{-1}$. The difference was assigned to two structural features of alkynylboronate 12: first, a substantial change in the C-O-B-C torsion angle that reduced the donation of electron density of the oxygen lone pairs to boron; second, the introduction of electronwithdrawing groups in the 3 and 3' positions of BINOL which pull out electron density from the oxygens, enhancing the Lewis acid character of the boron atom. As a result, alkynylboronate 12 coordinates to the enone giving complex $\mathbf{1 3}$, lowering the energy barrier of the subsequent conjugate addition. Finally, the enantiomeric excess was attributed to two close contacts between one of iodines of the chiral boronate 12 and two hydrogens of the enone in the transition structure (TS17) corresponding to the attack of the Re face. The difference of energy between the two diastereomeric transition states was in agreement with the experimental enantioselectivity. Also, the competing hetero Diels-Alder reactions towards cycloadduct 16 were computed to be disfavored by about $10 \mathrm{kcal} \mathrm{mol}^{-1}$.<smiles>[R]C=CC([R])=O</smiles>

1

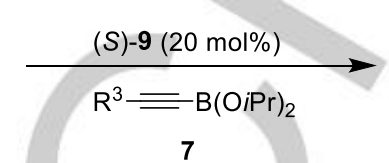

(3.0 equiv.)

$\mathrm{CH}_{2} \mathrm{Cl}_{2}$, r.t.-reflux

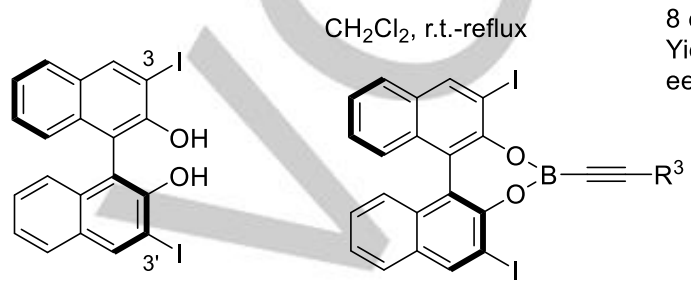

(S)-9<smiles>[R]C#CC([R])CC([R])=O</smiles>

8

8 examples Yields: $78-97 \%$ ee: $82-96 \%$
Scheme 3. Conjugate alkynylboration of enones catalyzed by (S)-3,3'-diiodo-BINOL (S)-16.

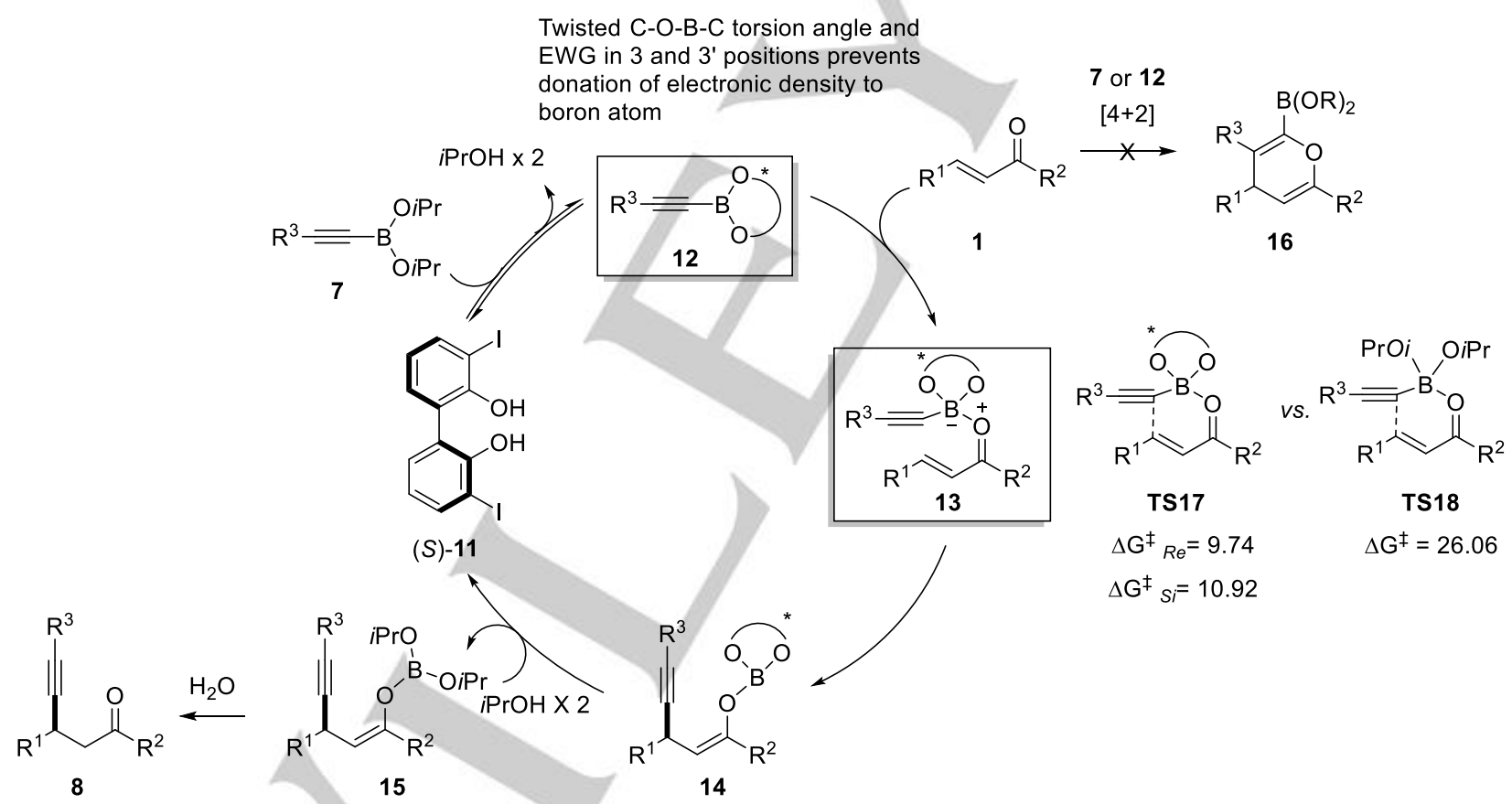

Scheme 4. Catalytic cycle for the organocatalyzed conjugate alkynylboration of enones. B3LYP/lacvp* energies in $\mathrm{kcal}^{*} \mathrm{~mol}^{-1}$.

In 2007, Chong et al. reported the organocatalytic asymmetric conjugate alkenylation of enones 19 using dimethyl alkenylboronates 20 to afford the $\beta$-adducts 21 using $(R)-3,3$ diiodo-BINOL $(R)-9$ as catalyst (Scheme 5$).{ }^{24}$ They postulated the cyclic transition state TS22a to account for the observed reactivity and the stereoselectivity, similar to the one found on the studies mentioned above. ${ }^{23}$ The reaction was applied in 25 examples including aromatic and heteroaromatic ring with both electron withdrawing and donor groups in the enone analogues and a broad substitution in the organoborane moiety. 


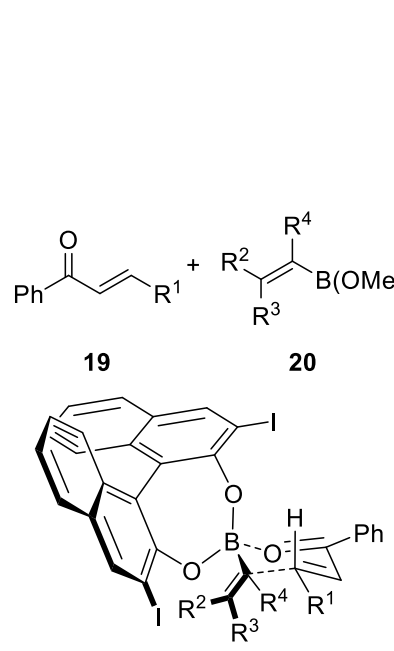

Six-membered chair-like TS22a Favored<smiles>Oc1c(I)cc2ccccc2c1-c1c(O)c(I)cc2ccccc12</smiles>

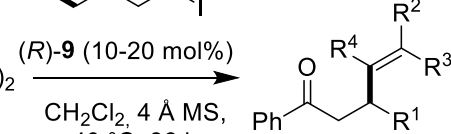
$40^{\circ} \mathrm{C}, 36 \mathrm{~h}$

21

25 examples Yields: $57-98 \%$ ee: $90-98 \%$

Diverse funcional groups in enone Broad substitution of the alkene

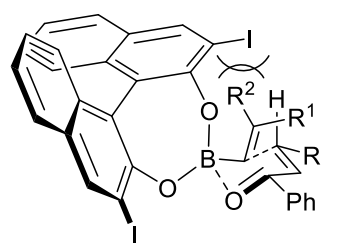

Six-membered chair-like TS22b Disfavored

Scheme 5. Asymmetric conjugate alkenylation of enones 19 and proposed competing transition states TS22a and TS22b.

With the aim of explaining the outcome of this reaction, an exhaustive DFT study using the B3LYP/6-31G*+LANL2DZ for iodine level of theory was reported (Scheme 6$).{ }^{25}$ The formation of the Lewis acidic alkenylboronate $\mathbf{2 4}$ (biphenol $\mathbf{1 1}$ was used as a model) has a penalty of $14.49 \mathrm{kcal} \mathrm{mol}^{-1}$ (DCM) but activates the boron species. This dioxaborolane interacts with the carbonyl moiety of the enone $\mathbf{2 5}$ forming the ate-complex $\mathbf{2 6}$, lowering the energy barrier for $\mathrm{C}-\mathrm{C}$ bond formation more than 17 $\mathrm{kcal} \mathrm{mol}^{-1}$ relative to that for the uncatalyzed reaction $(27.76 \mathrm{kcal}$ $\mathrm{mol}^{-1}$ for 23 vs. $10.22 \mathrm{kcal} \mathrm{mol}^{-1}$ for $\mathbf{2 4}$ through 26), via the sofalike transition structure TS27 rather than the chair-like transition structure TS22a originally proposed. ${ }^{24}$ The alternative reaction channel in which only one methoxy ligand of the alkenylboronate is exchanged as well as the pathways for the competitive heteroDiels-Alder reaction were also found to be kinetically disfavored by ca. $15 \mathrm{kcal} \mathrm{mol}^{-1}$ relative to conjugate alkenylboration. Single ligand exchange was first proposed by Schaus in 2006 for the asymmetric organocatalytic allylboration of ketones $\mathbf{3}$ (vide infra).

In 2011, May and co-workers demonstrated that the novel $(R)$-3,3'-bis-(pentafluoro-phenyl)-BINOL $(R)$-30 organocatalyzed the addition of alkenylboronic species $\mathbf{2 0}$ to indole-appended enones 29 (Scheme 7). ${ }^{26}$ The methodology provides the 1,4addition products 31 with very good yields (60-91\%) and ees (87$99 \%)$. The reaction was applied to a representative spectrum of substituted alkenyl- and alkynylboronic acid derivatives and a variety of $\beta$-indole enones. Interestingly, the formation of the $\mathrm{C}-\mathrm{C}$ bond is performed without protection of the indole nitrogen, an important achievement for the synthesis of natural products. ${ }^{27}$

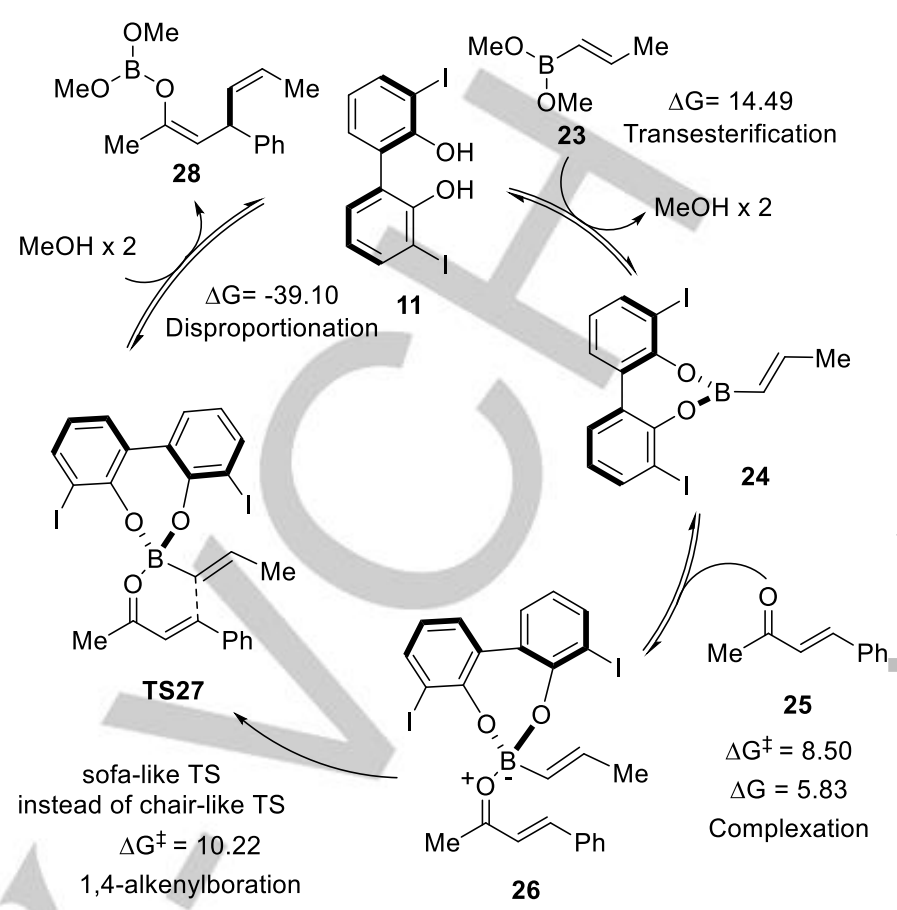

Re-exo TS (Si-exo TS +4.26)

$\Delta \mathrm{G}^{\ddagger}=27.76$

Background Reaction

Scheme 6. DFT study of the 1,4-addition of alkenylboronates to enones mediated by chiral BINOL $(R)-11$. Energies in kcal mol and DCM.

In 2012 a general and efficient method to synthetize $\alpha$ chiral heterocycles using perfluorinated BINOL catalysts $(R)-30$ $(\mathrm{R}=\mathrm{F})$ and $(R)-42\left(\mathrm{R}=\mathrm{CF}_{3}\right)$ was reported (Table 1). ${ }^{28}$ The methodology was applied to furans $\mathbf{3 2}$, thiophenes 33 , pyridines 34 , quinolines 35 , pyrazines 36 , thiazoles 37 , benzothiazoles 38 , pyrroles $\mathbf{3 9}$, indoles $\mathbf{4 0}$ and imidazoles $\mathbf{4 1}$. The approach also works for electron-rich enones.

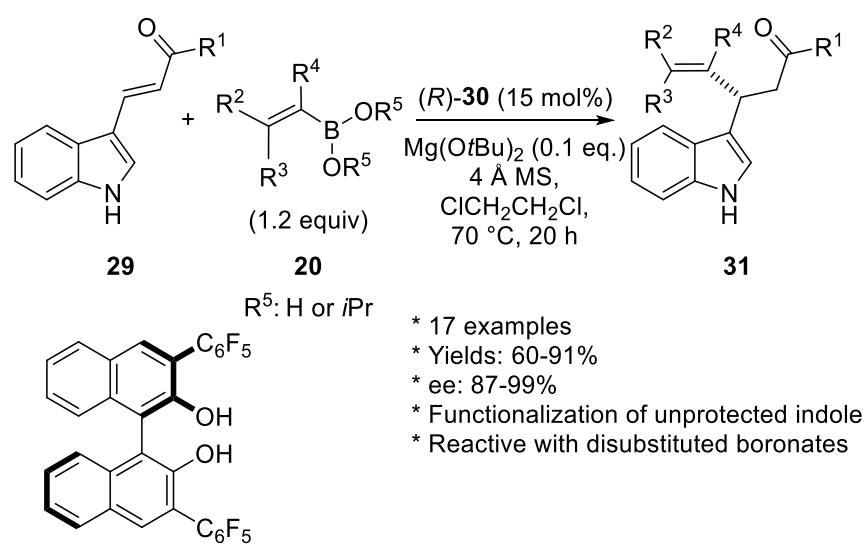
$(R)-30$

Scheme 7. Asymmetric 1,4-addition to indole-appended enones 29 catalyzed by BINOL $(R)-30$. 
Table 1. Asymmetric 1,4-addition of alkenylboronic acids to heterocycle-appended enones.<smiles>[R]C=CC(C)=O</smiles>

$(R)-30$ and $(R)-42$

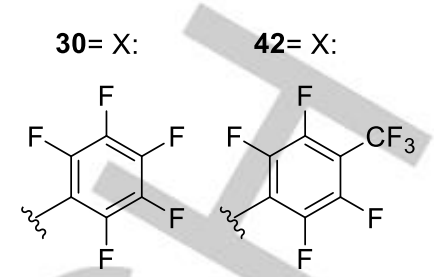
$\mathrm{F}$

\begin{tabular}{|c|c|}
\hline Compounds & Yields \\
\hline$\underbrace{O}_{32}$ & $\begin{array}{c}\text { (5 examples) } \\
(R)-30: 74-99 \% \\
(R)-42: 75-99 \%\end{array}$ \\
\hline
\end{tabular}<smiles>CC(=O)/C=C/c1cccs1</smiles>

33<smiles>CC(=O)/C=C/c1cccnc1</smiles>
(R)-30: $71-92 \%$ (R)-42: $91-95 \%$ 34<smiles>CC(=O)/C=C/c1ccc2ccccc2n1</smiles>

35<smiles>CC(=O)/C=C/c1cnccn1</smiles>

(R)-30: $64-96 \%$
(3 examples)

(R)-30: $85 \%$
$(R)-42: 94 \%$

$(R)-30: 85 \%$
$(R)-42: 94 \%$

(R)-30: $95 \%$ (R)-42: $99 \%$

(R)-30: $88-98 \%$ (R)-42: $90-94 \%$

(4 examples)

(R)-42: $90-99 \%$

(R) $-30: 76 \%$

(R)-42: $92 \%$

$(R)-30: 80-88 \%$
$(R)-42: 92-96 \%$

(R)-30: $72-96 \%$ (R)-42: $86-90 \%$

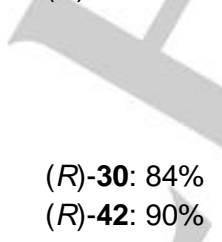
36

The same group reported an experimental mechanistic study of the conjugate addition of styrylboronic acids 44 to enones $\mathbf{4 3}$ mediated by BINOL 42 (Scheme 8). ${ }^{29}$ To determine the rate-determining step, they generated Hammett plots by introducing different substituents at the phenyl rings attached to the $\beta$-carbon and the carbonyl of the enone and of the styryl group of the boron nucleophile. The authors demonstrated that C-C bond formation from the complex $\mathbf{4 6}$ is the rate limiting step and proposed that the reaction rate depends on the stabilization of the positive charge in complex 46 . The presence of electronrich aromatic rings conjugated to the enone accelerates the reaction by increasing the electrophilic character of the $\beta$-carbon. Also, when electron-donating groups are introduced in the phenyl ring of the styrylboronic acid, the nucleophilic attack is easier, which increase the reaction rate. Therefore, the reaction

rate can be increased with the presence of electron-donating groups both in nucleophile and electrophile. 


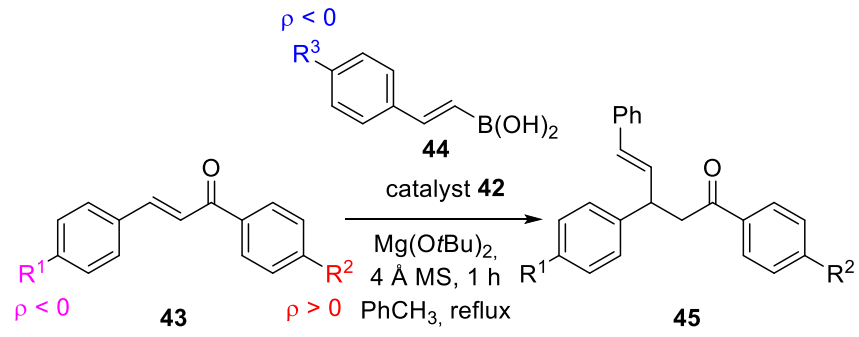

Higher rates for $\mathrm{R}^{1}=\mathrm{EDG}$, $\mathrm{R}^{2}=\mathrm{EWG}$ and $\mathrm{R}^{3}=\mathrm{EDG}$<smiles>Oc1c(C(F)(F)F)cc2ccccc2c1-c1c(O)c(C(F)(F)F)cc2ccccc12</smiles>

42

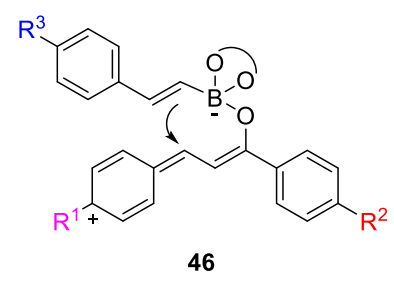

Rate determining step

Scheme 8. Experimental mechanistic study of the addition to enones catalyzed with BINOL 42 with Hammett plots.<smiles>[R]C([R])=CC=C1C=C2OCOC2=CC1=O</smiles><smiles>Cc1c(O)c(Br)cc2ccccc12</smiles><smiles>Cc1c(O)c(Br)cc2ccccc12</smiles>

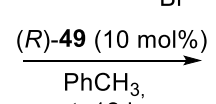
$\mathrm{rt}, 12 \mathrm{~h}$<smiles>[R]C([R])=C[C@@H]([Al])c1cc2c(cc1O)OCO2</smiles>

50 11 examples Yields: $46-85 \%$ er $>90: 10$<smiles>[R][R](OCC)B([R])OCC</smiles>
51 52

The reaction does not work with $\mathrm{H}$ or OMe instead of $\mathrm{OH}$ in aromatic ring

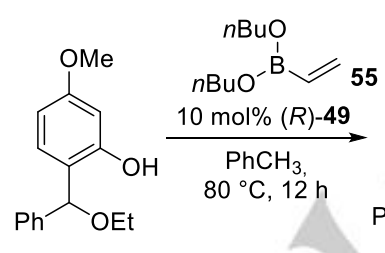

54

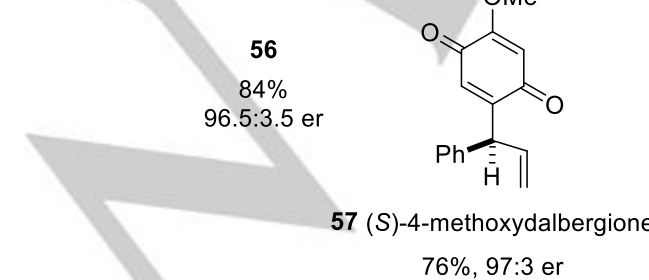

$76 \%, 97: 3$ er

Scheme 9. Asymmetric organocatalytic functionalization of 0 quinone methides 47 and ortho phenols 51 and synthesis of $(S)$ 4-methoxydalbergione (S)-57.
o-Quinone methides are novel and powerful motifs used in organic synthesis. ${ }^{30}(R)-3,3^{\prime}$-dibromo-BINOL $(R)-49$ was found to catalyze the addition of arylboronates as $\mathbf{4 8}$ to the benzylic position of ortho-quinone methide $\mathbf{4 7}$ to yield ortho substituted phenols 50 with er higher than 90:10 (Scheme 9). ${ }^{31}$ This versatile procedure was also extended to the reaction of hydroxybenzyl derivatives $\mathbf{5 1}$ with alkenylboronates $\mathbf{5 2}$ affording the bis-benzylic products $\mathbf{5 3}$ with very good yields (84-95\%) and enantiomeric excesses (>90\%). Also, the authors demonstrated the key role of the hydroxyl function in the aromatic ring, since the reaction did not work when it was replaced by hydrogen or methoxyde, and thus proposed the intermediacy of a o-quinone methide. As an application of this methodology, (S)-4methoxydalbergione $(S)-57^{32}$ was synthesized in high yield and er by treating phenol 54 with dibutyl vinylboronate $\mathbf{5 5}$ and catalyst $(R)-49$, followed by oxidation of the bis-benzylic vinyl intermediate $\mathbf{5 6}$ with Salcomine.

DFT calculations (optimizations at the B3LYP/6-31G** level of theory and single-points with M06-2X/LACVP ${ }^{* *}$ ) ${ }^{33}$ for 0 quinone methide 61 indicated that the addition reaction proceeds via a sofa-like six-membered ring transition structure (TS65) corresponding to a Lewis acid type activation as previously observed (Scheme 10). ${ }^{23,25}$ The mixed boronate 59 formed by exchange of one of the ligands with catalyst $(R)-49$ was computed to be more stable that the cyclic BINOL-derived intermediate 62 and therefore was predicted to be the most abundant of the intermediate species. However, the cyclic boronate 62 gave lower energy barriers ( 9.5 and $14.5 \mathrm{kcal} \mathrm{mol}^{-1}$ lower for the arylboration and alkenylboration, respectively), pointing to Lewis acid activation rather than the Brønsted acid activation via the mixed boronate 59. The transition structures corresponding to boronate 60 show a difference of $2.2 \mathrm{kcal} \mathrm{mol}^{-1}$ and $2.7 \mathrm{kcal} \mathrm{mol}^{-1}$ for the arylboration and the alkenylboration, respectively, favoring TS65Si relative to TS65Re. These differences agree with the experimentally observed enantiomeric ratios. The enantioselectivity seem to arise from destabilizing interactions between the side chain of the o-quinone methide and one of the bromines of the BINOL catalyst.

\subsection{Use of modified tartaric acid derivatives}

In 2010, Suguira and co-workers proved that O-monoacyl tartaric acids catalyzed the asymmetric conjugate addition of boronic acids to enones. ${ }^{34}$ After the screening of different catalysts led to the 3,5-di(tert-butyl)-benzoyl derivative 68 , diverse enones 1 were subjected to the conjugate addition of alkenyl and heterocyclic boronic acids 67 (9 examples) under mild conditions $\left(50-60{ }^{\circ} \mathrm{C}, 24-120 \mathrm{~h}\right)($ Scheme 11, Eq. 1). Yields varied from 46 to $92 \%$ and ees from $68 \%$ to $87 \%$.

In 2014, the strategy was extended to the asymmetric addition of styrylboronic acid $\mathbf{7 0}$ to dienones 69 mediated by catalyst 68 (Scheme 11, Eq. 2). ${ }^{35}$ The monostyrylated products were obtained with moderate to high yields 71 (52-81\%) and high enantiomeric excesses (86-94\%) when symmetrical dienones were used. The reaction was also carried out with unsymmetrical dienones affording products 71 with ca. $70 \%$ yield and $87 \%$ ee. With the monostyrylated products in hand, a 
ring closing metathesis with Hoveyda-Grubbs II catalyst (10 mol\%) afforded the optically active cyclopentenones 72 with variable yields ${ }^{36}$.

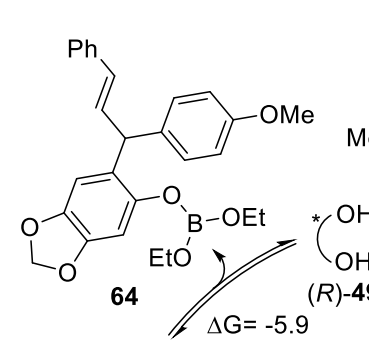<smiles>CCOB(OCCOc1ccccc1)Oc1cc2c(cc1C(/C=C/c1ccccc1)c1ccc(OC)cc1)OCO2</smiles><smiles>CCO</smiles>
$\Delta \mathrm{G}=-5.9$

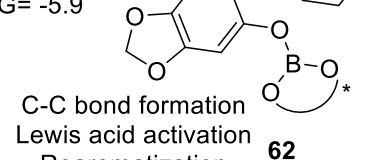
Rearomatization<smiles>CCOc1ccc([18O]c2ccc([15OH])cc2)cc1</smiles><smiles>Oc1c(Br)cc2ccccc2c1-c1c(O)c(Br)cc2ccccc12</smiles>

(R)-49

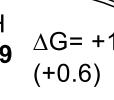<smiles>COc1ccccc1</smiles>
i. $-\mathrm{H}$ is ${ }^{1} O^{\prime}$

most abundant

$$
\begin{aligned}
& \Delta \mathrm{G}=+6.6 \\
& (+10.2)
\end{aligned}
$$<smiles>O</smiles>
$\Delta \mathrm{G}^{\ddagger}=+7.5$ $(-2.6)$<smiles>CCC(C)CC1C=C2OCOC2=CC1=CC=Cc1ccccc1</smiles>
61
23.8 (17.4) TS66 18.9 (12.5) 16.0

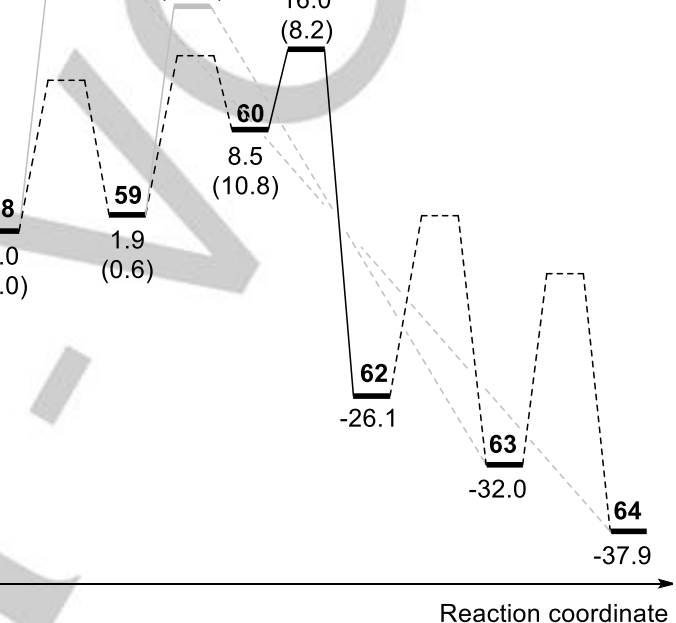

Lewis Acid Activation

Brønsted Acid Activation

$$
\text { (1) }
$$

TS66: wrong enantiomer for alkenylboration with experimental data

$\Delta \Delta \mathrm{G}^{\ddagger}=+9.5(+14.5)$

$\Delta \Delta \mathrm{G}^{\ddagger}{ }_{\mathrm{Re} / \mathrm{Si}}=+2.2(+2.7)$

Scheme 10. DFT study of the asymmetric arylation of $o$-quinone methide with $(R)-49$. Free energies for alkenylboration are shown between parentheses. Energies in $\mathrm{kcal} \mathrm{mol}^{-1}$. Dotted lines are drawn for all ligand exchange steps since the corresponding transition structures were not located.

To gain insight into the mode of action of this novel catalyst, in 2014 a DFT study at the B3LYP/6-311+G** level of theory of the asymmetric conjugate alkenylboration using $O$ monoacyl L-tartaric acids 73 was reported (Scheme 12). ${ }^{37}$ Ligand exchange of styrylboronic acid $\mathbf{7 0}$ with $\mathbf{7 3}$ affords the five membered acyloxyborane $74\left(\Delta \mathrm{G}=-0.09 \mathrm{kcal} \mathrm{mol}^{-1}\right)$. The proposed acyloxyboranes derived from $O$-monoacyltartaric acid as reactive species were first described by Yamamoto et al. and used as catalysts in different reactions. ${ }^{38}$ Then, coordination between the boron atom of $\mathbf{7 4}$ and the carbonyl oxygen of chalcone (75), gives rise to a coordination complex $\left(\Delta \mathrm{G}^{\ddagger}=\right.$ $\left.+18.28 \mathrm{kcal} \mathrm{mol}^{-1}\right)$. 
WILEY-VCH

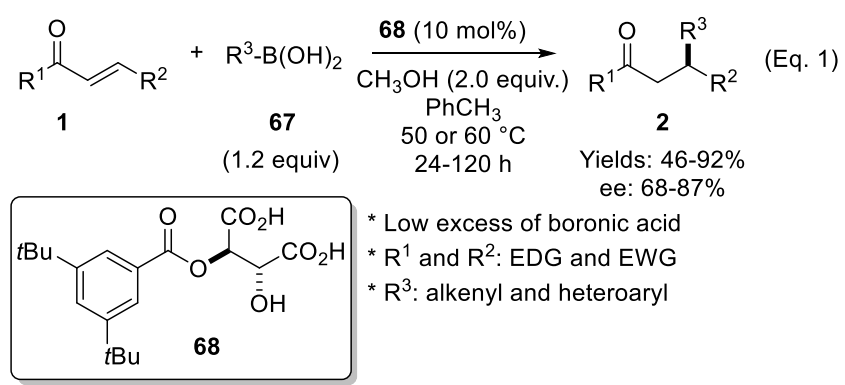

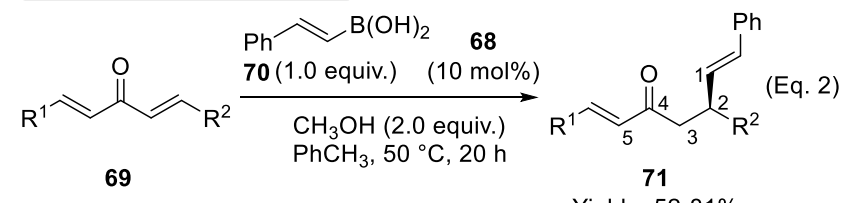

69

$$
\begin{aligned}
& \text { Hoveyda-Grubbs II Yields: } 52-81 \%
\end{aligned}
$$

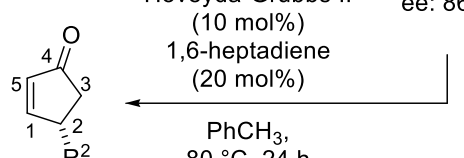

$$
\begin{aligned}
& 80^{\circ} \mathrm{C}, 24 \mathrm{~h} \\
& 72 \quad \text { *Applied to symmetrical and unsymmetrical } \\
& \text { Yields: } 48-98 \% \\
& \text { dienones } 69 \\
& \text { * Affords the monostyrylated product } \mathbf{7 2} \text { with } \\
& \text { good chemo- and enantioselectivity }
\end{aligned}
$$

Scheme 11. Asymmetric 1,4-addition of boronic acids to enones catalyzed by tartaric acid derivative 68 . Synthesis of chiral cyclopentenones 72 .

Interestingly, the complex is stabilized by a strong hydrogen-bonding interaction $(1.7 \AA$ ) between the hydrogen of the free carboxy group of the catalyst portion and the carbonyl oxygen of the cyclic acyloxyborane reducing the flexibility of the system and diminishing the energy barrier for the conjugate addition in $9.71 \mathrm{kcal} \mathrm{mol}^{-1}$ relative to the non-catalyzed reaction $\left(\Delta \mathrm{G}^{\ddagger}=35.00 \mathrm{kcal} \mathrm{mol}^{-1}\right.$ for 74 via TS76 vs. $\Delta \mathrm{G}^{\ddagger}=44.71 \mathrm{kcal} \mathrm{mol}^{-1}$ for 70). A special case of intramolecular Brønsted acid assisted Lewis acid catalysis (BLA) was thus proposed.

Frontier Molecular Orbitals (FMOs) analysis of the reactants and the geometries obtained are similar to those for the BINOL-catalyzed reactions. ${ }^{25}$ When the HOMO-LUMO gaps are calculated for the starting material $\mathbf{7 0}$ and for the acyloxyborane $\mathbf{7 4}$ reacting with chalcone $\mathbf{7 5}$, no significant differences are observed (ca. $\Delta \mathrm{E}>4.1 \mathrm{eV}$ ). However, the HOMO-LUMO gap for the complex was considerably lower $(\Delta \mathrm{E}=$ $2.47 \mathrm{eV}$ ). Thus, it was postulated that even if a small quantity of complex is formed, the intramolecular conjugate addition should take place promptly with formation of intermediate $\mathbf{7 7}$, affording product $\mathbf{7 8}$ and releasing the catalyst 73 .

The study also correctly predicted the experimentally observed $S$ configuration of the product 78 . The transition structure corresponding to the Re attack to the $\beta$ carbon (TS76) was found to be $1.5 \mathrm{kcal} \mathrm{mol}^{-1}$ more stable than that for the $S i$ approach. This energy difference was mainly attributed to nonclassical $\mathrm{C}\left(\mathrm{sp}^{2}\right)-\mathrm{H} \cdots \mathrm{O}$ hydrogen bond interactions between the carbonyl oxygen of the acyl substituent and two hydrogens of the alkenyl group.

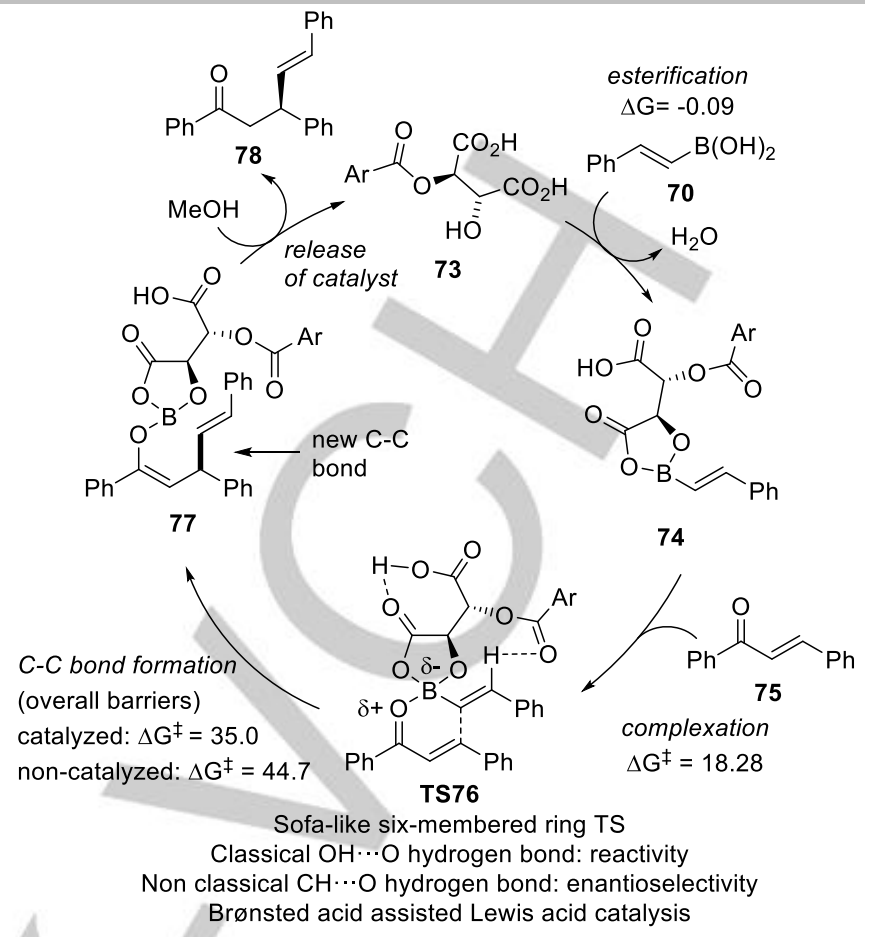

Scheme 12. DFT study of the asymmetric 1,4-addition of phenylboronic acid to chalcones using tartaric derivative acid $\mathbf{7 3}$ as catalyst. Energies are in $\mathrm{kcal} \mathrm{mol}^{-1}$.

Pellegrinet and coworkers reported that $\alpha$-hydroxyacids accelerate the Diels-Alder reaction of vinylboronic acid dibutyl ester 55 with cyclopentadiene (79) under microwave irradiation (Scheme 13). ${ }^{39}$ When the reaction was carried out with a stoichiometric quantity of (S)-mandelic acid (S)-80 excellent yields of $\mathbf{8 1}$ were obtained (93\%), while $30 \mathrm{~mol} \%$ afforded the bicyclic product with lower yield (2 h: 64\%, $3 \mathrm{~h}: 72 \%)$. Unfortunately, the enantioselectivity was very low (ee $<20 \%$ ).

$$
\text { via: }
$$

Scheme 13. Diels-Alder reaction of vinylboronic acid dibuty ester $\mathbf{5 5}$ with cyclopentadiene (79) accelerated by $(S)$-mandelic acid $(S)-80$. Energies in $\mathrm{kcal} \mathrm{mol}^{-1}$.

NMR studies and DFT calculations suggested that the activation of the dienophile occured by ligand exchange to give acyloxyborane 82. The free energy barrier for the Diels-Alder reaction of acyloxyborane $\mathbf{8 2}$ was computed to be ca. $3 \mathrm{kcal} \mathrm{mol}$ ${ }^{1}$ lower than one for the background reaction (33.81 vs. 36.62 $\mathrm{kcal} \mathrm{mol}^{-1}$ respectively) and the endo/exo diastereoselectivity reversed, as observed experimentally. This example demonstrated that $\mathrm{C}-\mathrm{C}$ bond formation with organoboranes can 
be organocatalyzed without previous coordination to the substrate.

\section{Asymmetric Organocatalytic 1,2- Additions}

1,2-Additions are the asymmetric organocatalytic reactions with organoboron compounds that have been developed to a greater extent, particularly in the last years. These strategies have been applied to ketones, aldehydes, $\mathrm{N}$-acylimines, and also to isobenzopyrilium derivatives to give the enantioenriched products with high yields and enantiomeric ratios. Mostly, the catalysts comprise 3,3'-functionalized BINOLs and the derived phosphoric acids that activate the boronate moiety via Lewis or Brønsted acid activation. Thioureas have been used too but no mechanistic studies have been carried out so far. Several reviews about this topic cover the different strategies from a methodological point of view. ${ }^{40}$ In this section, we describe the mechanistic studies of asymmetric organocatalytic 1,2-addition reactions, which highlight the vast diversity of strategies.

\subsection{Use of chiral BINOLs}

Schaus et al. reported the first example of asymmetric organocatalytic 1,2-addition using organoboranes in $2006^{41}$ shortly after the report by $\mathrm{Wu}$ and Chong. ${ }^{16}$ The asymmetric allylboration of ketones $\mathbf{3}$ catalyzed by (S)-3,3'-dibromo-BINOL (S)-49 provided the tertiary homoallylic alcohols 84 enantioselectively (Scheme 14). The reaction was carried out with $15 \mathrm{~mol} \%$ of $(S)-49$ and a mixture of solvents $\left(\mathrm{PhCF}_{3} / \mathrm{PhMe}\right.$ 3:1) at low temperature.
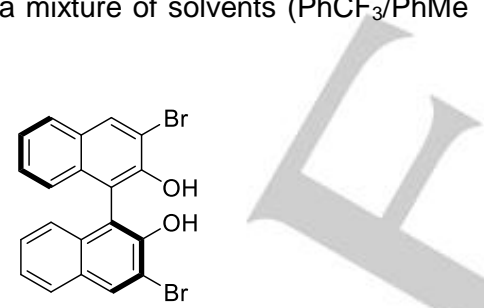

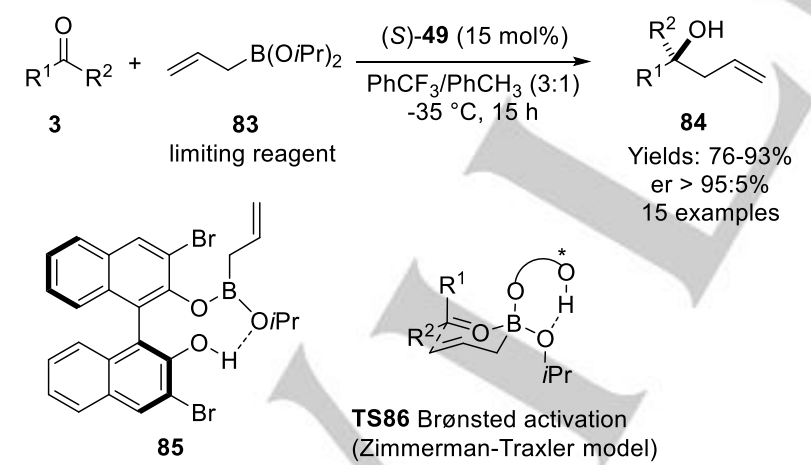

Proposed by ${ }^{1} \mathrm{H}$ NMR

Scheme 14. Asymmetric allylboration of ketones catalyzed by (S)-49. Proposal of Brønsted-acid activation.

Different aryl and heteroaryl ketones and also $\alpha, \beta$ unsaturated ketones were employed to obtain a broad diversity of derivatives 84 ( 15 examples) with very good yields (76-93\%) and enantioselectivities above 95:5. In addition, the reaction of acetophenone with $(E)$ - and $(Z)$-crotylboronic esters under the same conditions provided the 1,2-addition products with excellent diastereo- and enantioselectivities.
Based on ${ }^{1} \mathrm{H}$ NMR experiments, the authors observed a rapid transesterification of an isopropoxi ligand on the boron atom with a hydroxy group of the BINOL, affording intermediate 85. This structure was proposed be responsible for the high reactivity and enantioselectivity observed in the reaction. The authors proposed that the activation of the boron species in $\mathbf{8 5}$ could be imparted by a hydrogen bonding between the free hydroxyl of the BINOL and the remaining isopropoxy oxygen bonded to the boron atom, leading to Si facial attack on the ketone in a chair-like TS model (TS86). Furthermore, through a kinetic study, the authors observed that the reaction was first order in catalyst, with a positive linear effect of the ee of catalyst in the yield and positive but nonlinear effect in ee of the product.

The scope of the 1,2-additions was extended to the asymmetric allylboration of acylimines $\mathbf{8 7}$ with diisopropyl allylboronic ester 83 catalyzed by chiral (S)-3,3'-diphenyl-BINOL (S)-88 (Scheme 15). ${ }^{42}$ In general, the reaction provided acylamines 90 with very good yields (76-94\%) and high enantiomeric ratios (ee: 90 to $99 \%$ ) (24 examples). However, yields and enantioselectivities for a few carbamates and aliphatic imines were considerably lower.

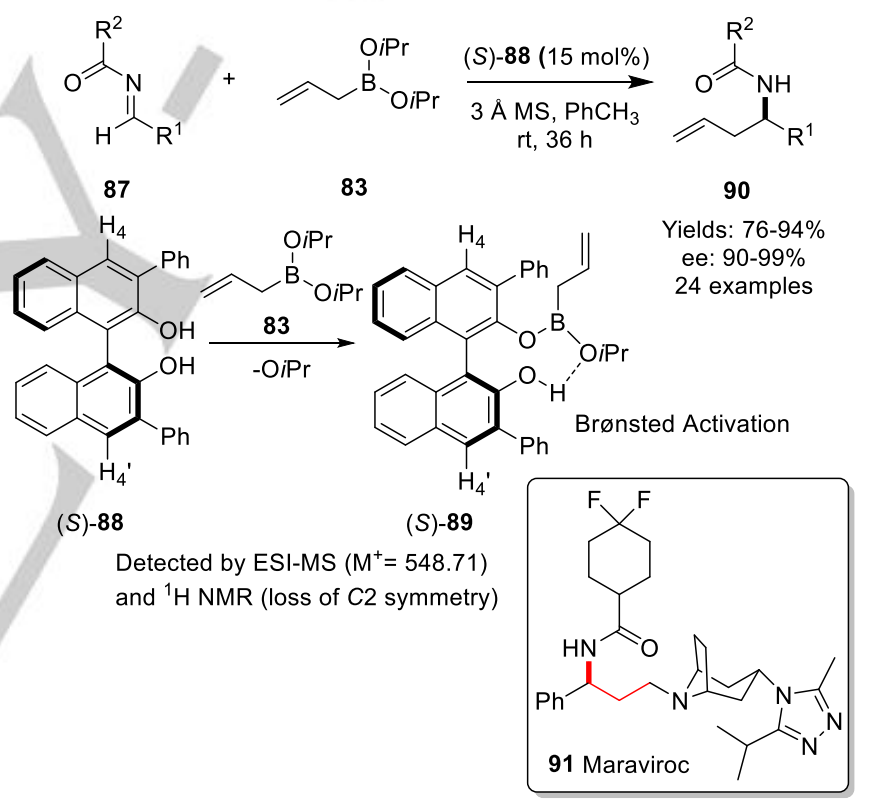

Scheme 15. Asymmetric 1,2-addition to acylimines catalyzed by $(S)$-88. Detection of intermediate (S)-89 and structure of Maraviroc 92.

Interestingly, the chiral BINOL that performed best for this reaction (S)-88 had phenyl substituents instead of EWGs as for the examples aforementioned. The transformation was applied to an alternative route for the synthesis of Maraviroc 92, a CCR5 antagonist against $\mathrm{HIV}^{43}$

In order to understand the mechanism of the reaction, the authors carried out NMR and ESI-MS studies (Scheme 15) similar to the one mentioned above. ${ }^{41}$ Accordingly, (S)-88 was mixed with allyldiisopropoxy borane $\mathbf{8 3}$ and loss of C2 symmetry was observed in the NMR signals of $\mathrm{H} 4$ and H4'. Since the cyclic boronate proposed based on DFT studies has C2 symmetry, ${ }^{23,25}$ the NMR signals are a clear evidence of the existence of an unsymmetrical engagement of the oxygens in 
(S)-89. Moreover, intermediate 89 was observed as the predominant species in the MS experiment $\left(\mathrm{M}^{+}: 548.71\right)$.

In 2009, an exhaustive kinetic study about the mechanism of the asymmetric allylboration of ketones catalyzed by chiral BINOL (S)-49 was reported. ${ }^{44}$ The aim of the study was to reduce the loading of the catalyst $(S)-49$ by evaluating the role of both the catalyst and the isopropanol in the catalytic cycle (Scheme 16).

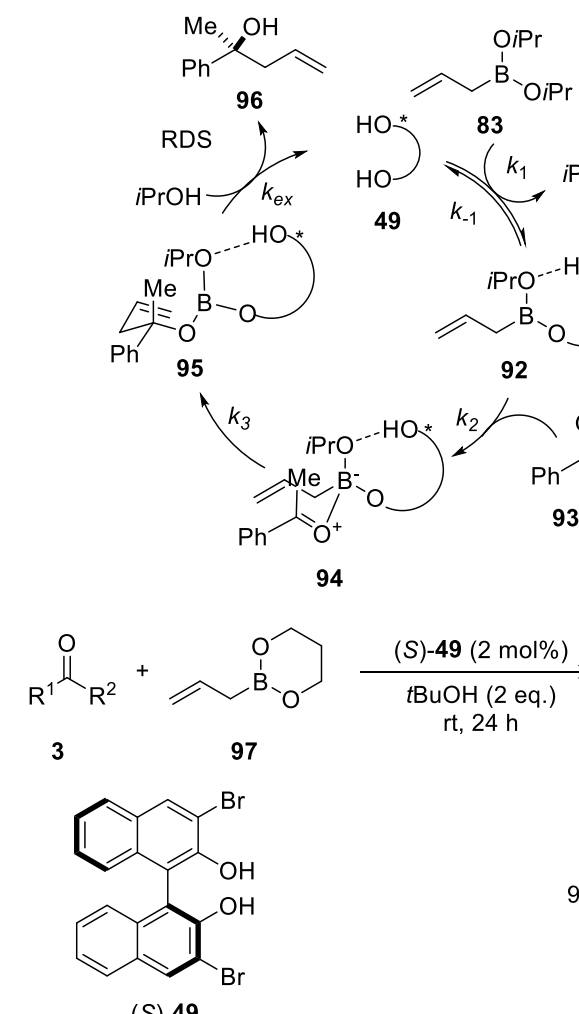

(S)-49

Scheme 16. Kinetic study and improvement of the asymmetric allylboration of ketones catalyzed by BINOL (S)-49.

The reaction rate and er were shown to increase with the concentration of isopropanol. Based on such results, the authors concluded that the rate-determining process is the final exchange of ligands that liberates the product and that the corresponding rate-constant $\left(k_{\mathrm{ex}}\right)$ is $[\mathrm{PrOH}]$ dependent. As a result, the use of an external alcohol would increase the quantity of free BINOL catalyst 49 and then, less loading of catalyst would be required. Also, the use of a more stable cyclic boronate 97 would allow to increase the reaction temperature. Indeed, when the cyclic allyl boronic ester 97 and the ketone $\mathbf{3}$ were mixed in presence of $2 \mathrm{~mol} \%$ of catalyst (S)-49 and 2 equivalents of $\mathrm{tBuOH}$ at $\mathrm{rt}$ for $24 \mathrm{~h}$, the tertiary homoallylic alcohols 96 were obtained with yields from 88 to $98 \%$ and enantiomeric ratios above 98:2 (16 examples). With this methodology, even the allylation of enolizable $\beta$-ketoesters occured efficiently. In addition, the transformation could be scaled ( $5 \mathrm{~g}$ of acetophenone) with recovery of $90 \%$ of catalyst (S)-49. The authors also demonstrated that, although the cyclic boronate 97 seems to be more sensitive to Lewis base coordination than isopropylboronate $\mathbf{8 3}$, the same reaction mechanism operates.

In 2009, a computational DFT study of the organocatalyic allylboration of ketones at the B3LYP/6-31G* level of theory was published (Scheme 17). ${ }^{45}$ The results of the calculations suggested that the chiral reactive species is the cyclic boronate 98 instead of the boronate $\mathbf{9 2}$ originally proposed (Schemes 15 and 16). ${ }^{41,42}$ In agreement with the results of ${ }^{1} \mathrm{H}$ NMR experiments, the formation of $\mathbf{9 8}$ was computed to require 7.59 $\mathrm{kcal} \mathrm{mol}{ }^{-1}$ more than that of $\mathbf{9 2}$, and therefore the latter should be more abundant. However, strong complexation to the ketone is highly favorable for $98\left(\Delta \mathrm{G}=-6.87 \mathrm{kcal} \mathrm{mol}^{-1}\right)$ and the energy barrier for the resulting 100 (Lewis acid activation) is $4.87 \mathrm{kcal}$ $\mathrm{mol}^{-1}$ lower than the one for intermediate 94 (Brønsted acid activation) so 98 should be the most reactive species. Furthermore, for intermediate 92 the wrong enantiomer 95 was predicted to be favored while cyclic boronate 98 afforded the correct enantiomer 102. It is important to point out though that, as in previous studies, ${ }^{23,25}$ the transition structures for the exchange of ligands were not located.

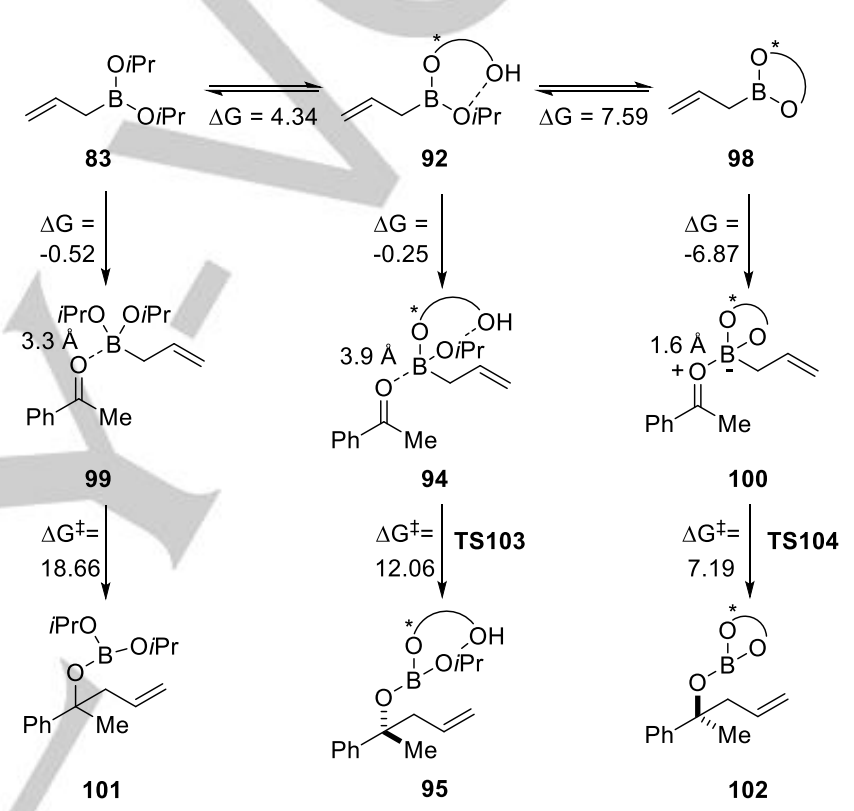

$\Delta \mathrm{G}=-20.92$

$$
\Delta \mathrm{G}=-23.99
$$

calcd. $\mathrm{Re} / \mathrm{Si}=99: 1$ wrong enantiomer

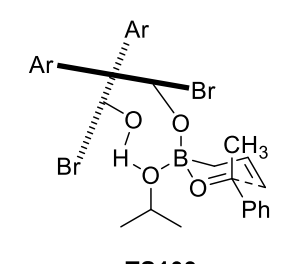

TS103

Brønsted acid activation

$$
\Delta \mathrm{G}=-17.69
$$

calcd. SilRe $=100: 0$ correct enantiomer

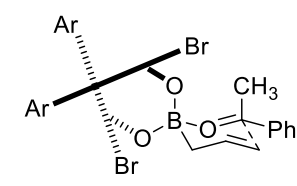

TS104

Lewis acid activation
Scheme 17. DFT study of the allylboration of acetophenone: Brønsted vs. Lewis acid activation. Energies in $\mathrm{kcal} \mathrm{mol}^{-1}$.

With the aim of expanding the use of acylimines 106 to obtain a variety of chiral amines 107 , Schaus et al. were able to install diverse carbon moieties by optimizing the BINOL catalyst for each case (Scheme 18). ${ }^{46}$ (S)-3,3'-Dibromo-BINOL (S)-49 served as the optimal organocatalyst for the addition of arylboronates $105\left(R^{1}=\mathrm{Ar}\right)$ to acyl imines 106 affording 12 examples of enantioenriched acylamines 107 with yields from 70 to $98 \%$ and ee above $91 \%$. 


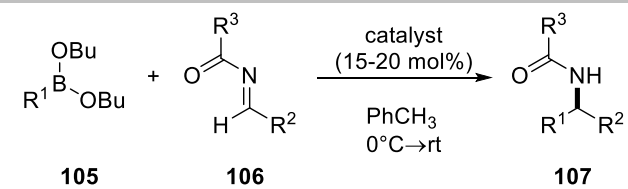

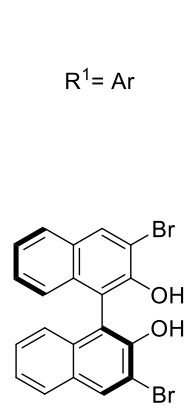

(S)-49

arylboration

12 examples

Yields: $70-98 \%$

er: $95.5: 4.5-98: 2$

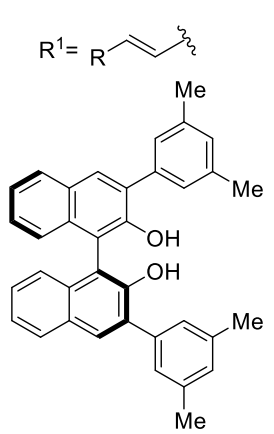

(S)-108

alkenylboration

11 examples

Yields: $74-91 \%$ er: 95:5-99:1
107

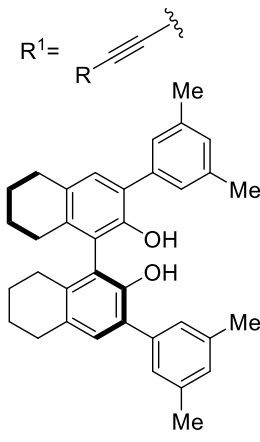

(S)-109

alkynylboration

11 examples

Yields: $62-99 \%$

er: $92: 8$ to $97: 3$
Scheme 18. Screening of chiral catalysts for additions to acylimines.

Also, (S)-3,3'-bis(3,5-bis(methyl)phenyl)-BINOL (S)-108 catalyzed the alkenylboration of acylimines 106 obtaining the corresponding alkenyl acylamines (11 examples) with yields between 74 and $91 \%$ and ee above $90 \%$. Moreover, for the asymmetric organocatalytic alkynylboration the octahydro analogue (S)-109 was used giving the corresponding alkynyl acylamines with yields between 62 and $99 \%$ and ee higher than $86 \%$ ( 11 examples).<smiles>CCCCOB(OCCC)c1ccc(Cl)cc1</smiles><smiles>O=CC=Cc1ccccc1</smiles>

110
111

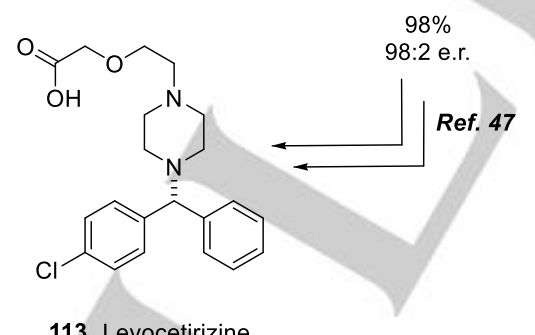

113, Levocetirizine

Scheme 19. Formal synthesis of levocetirizine 113.

The methodology was used to obtain 112, an intermediate for the formal synthesis of levocetirizine 113 (Xyzal), ${ }^{47}$ an antihistaminic drug (Scheme 19). Reaction of $p$ chlorophenylboronate $\mathbf{1 1 0}$ and acylimine $\mathbf{1 1 1}$ afforded the diaryl intermediate 112 with $98 \%$ yield and $96 \%$ ee.

Once again, the authors attribute the catalytic activity of BINOLs to Brønsted acid activation resulting from the exchange of only one of the alcoxy goups ${ }^{41}$ in 114 based on ESI-MS experiments, forming the intermediate 117 (Scheme 20).

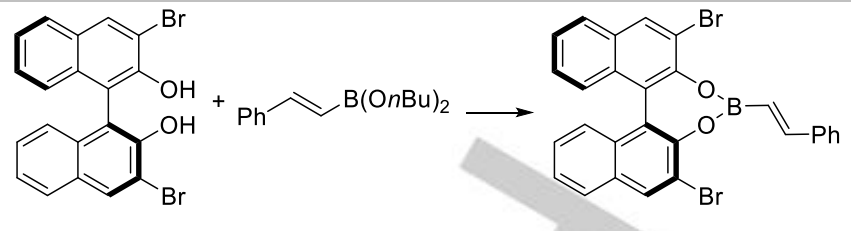

(S)-49

114

115

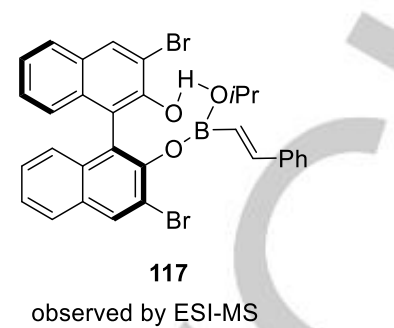

observed by ESI-MS

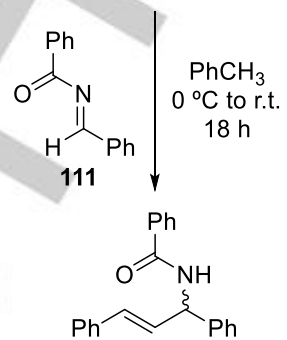

116

$20 \%$ yield $55: 45$ er
Scheme 20. Brønsted acid activation proposed for the organocatalytic reaction of acylimines.

Further evidence to support such hypothesis was obtained by synthesizing the chiral cyclic boronate $\mathbf{1 1 5}$ derived from BINOL (S)-49 and (E)-styrylboronate 114, which gave a yield lower than $20 \%$ and $55: 45$ er of 116 when reacted with benzoylbenzimine 111 under the same reaction conditions.

However, allylboration of acetophenone 93 with the allylboronate derived from $3,3^{\prime}-\mathrm{diCF}_{3} \mathrm{BINOL}(R)-117^{48}$ gave essentially the same er as the one obtained in the organocatalytic reaction using the $3,3^{\prime}$-diBr-BINOL (S)-49 under similar conditions, albeit in lower yield (Scheme 21, Eqs. 1 and 2, respectively) (Scheme 21). ${ }^{41}$

The scope of the enantioselective organocatalyzed boronate 1,2-additions was expanded by the development of the asymmetric propargylation of ketones with allenylboronate $\mathbf{1 1 8}$ catalyzed by (S)-3,3'-dibromo-BINOL (S)-49 (Scheme 22). ${ }^{49}$ The reactions were run at $60{ }^{\circ} \mathrm{C}$ for $1 \mathrm{~h}$ under microwave irradiation in neat conditions and applied to 22 ketones with a great diversity of functional groups. When $\alpha, \beta$-unsaturated ketones were used, complete chemoselectivity towards the 1,2-addition products 119 was observed. Yields varied between $60-98 \%$, and the enantioselectivities were $79: 21$ to $99: 1$.

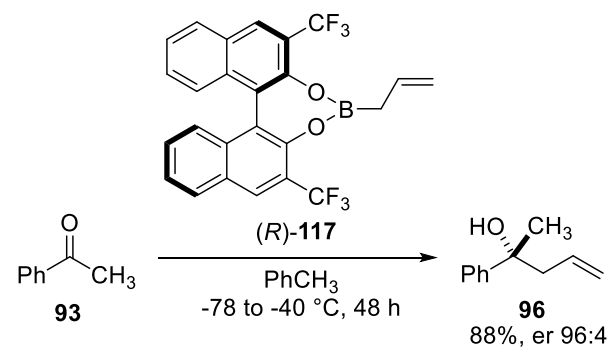

(Eq. 1)

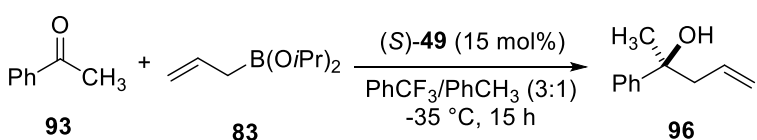

$83 \%$, er $97: 3$

Scheme 21. Comparison of stoichiometric and catalytic asymmetric allylboration of acetophenone. 
The authors proposed a transition state based on Brønsted-activation of the organoborane. The use of racemic allenylboronic esters monosubstituted at the terminal carbon gave the syn products with high diastereo- and enantioselectivities, resulting from a kinetic resolution process. The observed diastereoselectivity was rationalized on the basis of the unfavorable gauche interactions of the terminal substituent with the methyl and phenyl groups of acetophenone.

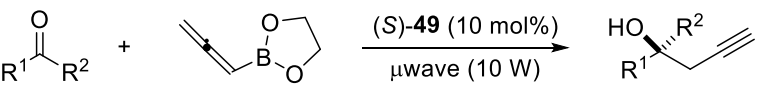

$$
\begin{aligned}
& \begin{array}{llll}
3 & 118 & 1 \mathrm{~h} & \mathbf{1 1 9}
\end{array} \\
& \text { Yields: } 60-98 \% \\
& \text { ee: } 58-98 \%
\end{aligned}
$$

Scheme 22. Asymmetric organocatalyzed propargylation of ketones under microwave irradiation.

This reaction was theoretically studied at the M062X/LACVP**//B3LYP/6-31G** level of theory and the activation was predicted to occur via Lewis acid catalysis rather than Brønsted acid catalysis (Scheme 23). ${ }^{50}$ Although the TS corresponding to Brønsted activation (TS121) presented a free energy barrier lower than that of the background reaction TS120 $\left(\Delta G^{ \pm}=16.5\right.$ and $24.1 \mathrm{kcal} \mathrm{mol}^{-1}$, respectively), this activation mode afforded the wrong enantiomer. In addition, the barrier for Lewis activation through the formation of the cyclic boronate (TS122) was much lower $\left(\Delta \mathrm{G}^{ \pm}=9.9 \mathrm{kcal} \mathrm{mol}^{-1}\right)$ and the predicted enantioselectivity was in accordance with the experimental results. It is important to mention though that, when the prerequisite exchange of ligands was taken into consideration, the pathway corresponding to TS122 was computed to be preferred only by $2.9 \mathrm{kcal} \mathrm{mol}^{-1}$ using a solvation model (PCM in acetophenone).

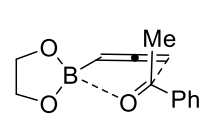

TS120

Background Reaction: $\Delta \mathrm{G}^{\ddagger} \quad 24.1$ $\Delta \mathrm{G}_{\text {Soln }} \neq 27.0$

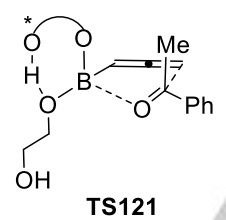

Brønsted Activation: 16.5
21.7

Wrong enantioselectivity Right enantioselectivity
Scheme 23. Competing TSs (TS120-122) located by a DFT study of the asymmetric 1,2-adittion of allenylboronate to acetophenone. Energies in $\mathrm{kcal} \mathrm{mol}^{-1}$

Szabó et al. reported the synthesis of adjacent quaternary stereocenters in $\mathbf{1 2 5}$ by asymmetric organocatalyzed allylboration of ketones $\mathbf{1 2 3}$ with $\mathrm{y}, \mathrm{\gamma}$-disubstituted allylboronic acids 124 (Scheme 24). ${ }^{51}$ Full control of the diastereo- and enantioselectivity was achieved in a stereodivergent approach by the choice of the BINOL catalyst and the diastereoisomeric prenylboronic acid. ${ }^{19} \mathrm{~F}$ NMR experiments suggested the generation of the cyclic boronate derived from 3,3'difluoroBINOL by double ligand exchange, which was accelerated by the addition of molecular sieves either in combination with $t-\mathrm{BuOH}$ or not. On the contrary, $i-\mathrm{PrOH}$ inhibited the formation of the cyclic diester, probably by esterification of the boronic acid, which was observed by ${ }^{1} \mathrm{H}$
NMR. $t$-BuOH also increased the enantioselectivity probably by regenerating the BINOL catalyst. The six-membered chair-like transition structures TS126 and TS127 were proposed to explain the stereochemical outcome of the reactions. TS127 leading to the minor enantiomer should be disfavored by steric repulsions between one of the susbtituents of the BINOL ( $\mathrm{X}=\mathrm{Br}$ in $\mathbf{4 9}$ or I in 9) and the methyl group of the ketone.

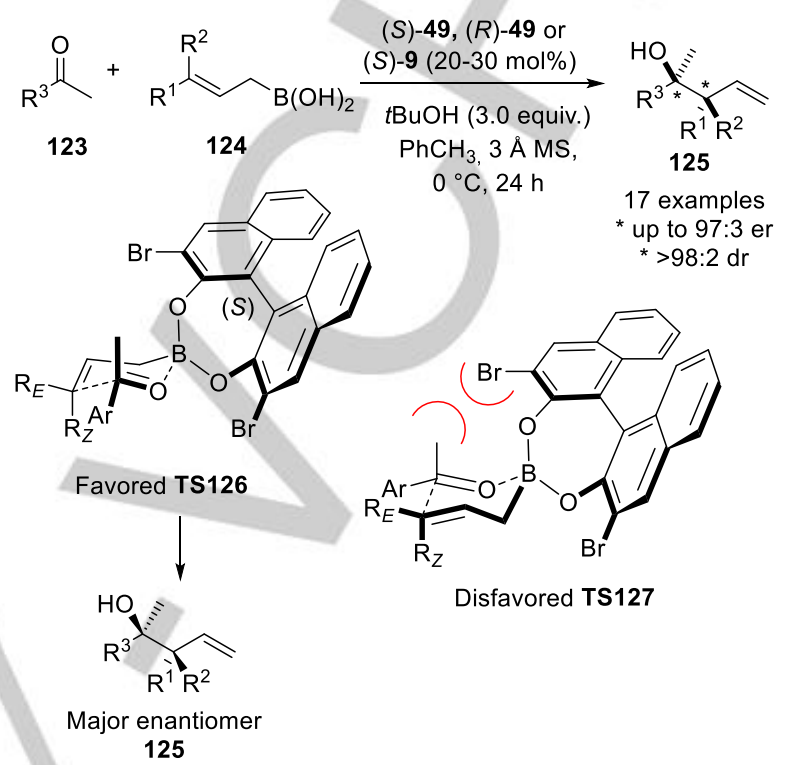

Scheme 24. Asymmetric organocatalyzed allylboration of ketones 123.

The reaction was later extended to the asymmetric organocatalytic allylboration of indoles 128 (Scheme 25). ${ }^{52}$ The prenylated products $\mathbf{1 3 0}$ were obtained with high yields and stereoselectivities. Interestingly, when 3-methylindoles such as skatole (132) were used, three adjacent stereocenters were obtained. This work is another excellent example of functionalization of indoles without protection of the nitrogen. ${ }^{31,32}$ The high stereoselectivity of the reaction of skatole with geranylboronic acid $\mathbf{1 2 9}$ was rationalized by a dynamic kinetic resolution of the enantiomeric imine tautomers 131 and ent-131 and a Zimmerman-Traxler model TS133 that minimizes the steric repulsions. The addition of an external alcohol $(\mathrm{MeOH})$ was proposed to inhibit the background reaction by formation of the less reactive dimethylboronic ester and, at the same time, to facilitate the liberation of the catalyst. Dihydroisoquinoles were also prenylated efficiently under similar conditions.

A theoretical DFT study (B3LYP-D3(BJ)/6$311+G(2 d, 2 p), S D D / / B 3 L Y P / 6-31 G(d, p)$,lanl2dz) supported the proposed mechanism and gave further insight. ${ }^{53}$ First, the imine tautomers 131 were computed to be $13.0 \mathrm{kcal} \mathrm{mol}^{-1}$ less stable than skatole 132 (Scheme 25). In addition, exergonic dehydration of boronic acid was predicted to give the more reactive allylboroxine. However, reaction with methanol was calculated to be more favorable. The cyclic BINOL-derived boronate TS133, also formed by an exergonic process, exhibited higher Lewis acidity giving a more stable complex with the imine and a resulting lower energy barrier. The high stereoselectivity was correctly reproduced by the calculations and explained by steric repulsions between different substituents of the indole and either the BINOL or the allyl portion of the cyclic boronate in the less favorable approaches $\left(\Delta \Delta \mathrm{G}^{\ddagger}>5.8 \mathrm{kcal} \mathrm{mol}^{-1}\right)$. 
WILEY-VCH<smiles>[R]c1c[nH]c2ccccc12</smiles>

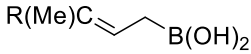

$(E)$ - or $(Z)-129$

$\stackrel{(R) \text { or }(S)-49(15 \mathrm{~mol} \%)}{\longrightarrow}$ $\mathrm{MeOH}(3.0$ equiv. $)$
$\mathrm{PhCH}_{3}, 3 \mathrm{~A} \mathrm{MS}$, $40^{\circ} \mathrm{C}, 48 \mathrm{~h}$<smiles>[R]C1=C2Nc3ccccc3N2C1[R]</smiles>

130

15 examples $60-94 \%$ $99: 1$ d.r.<smiles>Cc1c(C=Cc2cccc3c2[nH]c2ccccc23)[nH]c2ccccc12</smiles>
$131 \mathrm{G}_{\mathrm{rel}}=13.0$ 132 ent-131

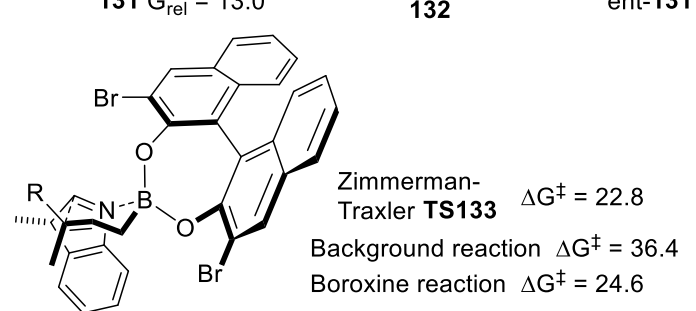

Scheme 25. Asymmetric organocatalyzed allylboration of indoles. Energies in $\mathrm{kcal} \mathrm{mol}^{-1}$.

\subsection{Use of modified BINOL-derived phosphoric acids}

In 2010, Jain and Antilla reported the asymmetric allylboration of aldehydes $\mathbf{1 3 4}$ with allylboronic acid pinacol ester (135) catalyzed with BINOL-derived chiral phosphoric acids such as ( $R$ )-TRIP-PA $(R)$-136 (Scheme 26$).{ }^{54}$ Secondary homoallylic alcohols 137 were obtained under smooth conditions (toluene, $30{ }^{\circ} \mathrm{C}$ ) with excellent yields (91-99\%) and very good to excellent ees $(73-99 \%)$. In addition, crotylboration of benzaldehyde was shown to take place with excellent yields and diastereo- and enantioselectivities. The authors proposed a TS with Brønsted acid activation of the boronate in which the acidic proton of the chiral phosphoric acid forms a hydrogen-bond with the pseudoequatorial oxygen of the boronate (TS138). This methodology paved the way to the use of chiral phosphoric acids as organocatalysts in organoborane reactions. Also, this type of Brønsted acid catalysis does not require that the organoboron compound undergoes transesterification with the chiral organocatalyst. As a result, more stable boronic esters such as pinacol derivatives can be used.

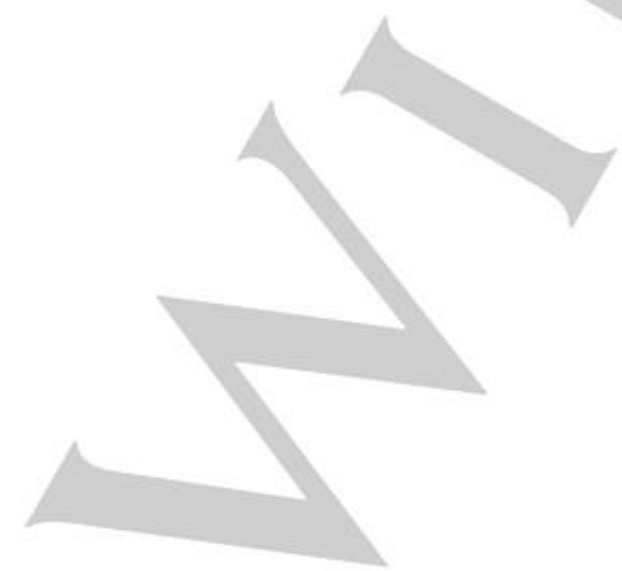

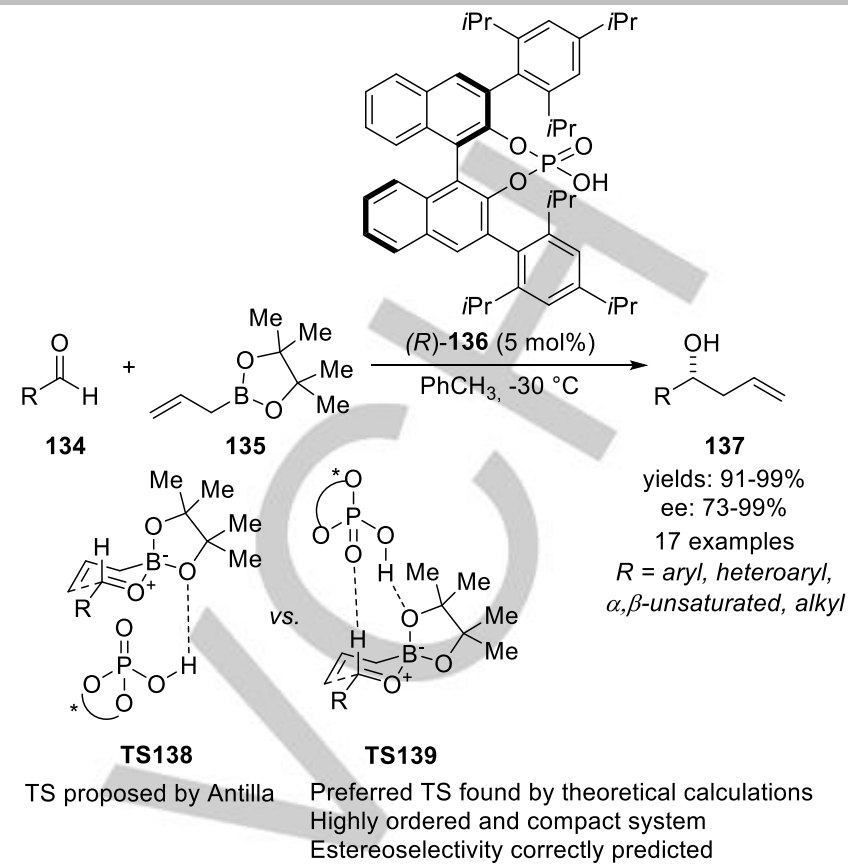

Scheme 26. Asymmetric allylboration of aldehydes catalyzed by (R)-136.

In 2012, a mechanistic study of the reaction was described. ${ }^{55}$ Both DFT B3LYP/6-31G* calculations on a simplified biphenol model and hybrid DFT-QM/MM calculations on the whole system with ONIOM(B3LYP/6-31G**:UFF) followed by $M 06-2 X / 6-31 G^{* *}$ single points indicated that the reaction takes place through the highly ordered and compact sixmembered transition state TS139 (Scheme 26), involving two hydrogen bonds. The chiral phosphoric acid simultaneously acts as a donor with the pseudoaxial oxygen of the boronate and as an acceptor through the non-classical interaction between the phosphoryl oxygen and the formyl hydrogen of the aldehyde. TS139 was computed to be ca. $3 \mathrm{kcal} \mathrm{mol}^{-1}$ more stable than the TS originally proposed (TS138) and $6 \mathrm{kcal} \mathrm{mol}^{-1}$ lower in energy than the one for the background reaction..$^{54}$ Moreover, the model correctly reproduced the observed enantioselectivity, which also helped correct the missassigned absolute configuration of one of the products. ${ }^{56}$

In 2012, the groups of Antilla and Reddy almost simultaneously reported the asymmetric 1,2-addition of allenylpinacol boronate (140) to aldehydes 134 to form the homopropargylic alcohols $\mathbf{1 4 1}$ with excellent yields and enantioselectivities (Scheme 27). ${ }^{57,58}$ 
WILEY-VCH

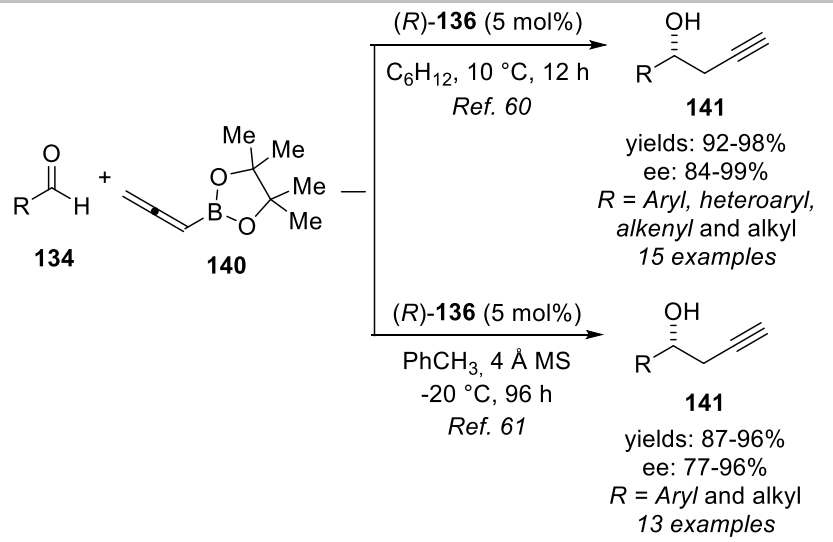

Scheme 27. Asymmetric propargylation of aldehydes catalyzed by phosphoric acid $(R)-\mathbf{1 3 6}$.

The authors proposed different transition structures to explain the experimental results (Scheme 28). Antilla and coworkers proposed single-point binding of the chiral phosphoric acid to the pseudoequatorial oxygen of the boronate (TS143) and located the corresponding transition structures computationally using a biphenol model. On the other hand, Reddy proposed Brønsted acid activation of the aldehyde with simultaneous $\mathrm{H}$-bonding between the phosphoryl oxygen and the hydrogen atom of the formyl group (TS 144). A theoretical study at the M06-2X/LACVP**//B3LYP/6-31G* level of theory first investigated the preferred reaction pathway using buta-1,3diene-1,4-diol-phosphoric acid (145) as a model for the catalyst. ${ }^{59}$ The results were refined with the biphenol model previously used by Antilla et al. and finally with the full catalyst. The calculations indicated that the TS for the background reaction TS142 as well as TS143 and TS 144 were more than 5 $\mathrm{kcal} \mathrm{mol}^{-1}$ higher in energy than the TSs in which the pseudoaxial oxygen of the boronate is activated by the acidic hydrogen of the catalyst and the hydrogen of the aldehyde interacts with phosphoryl oxygen (TS146, Goodman model). Also, the energy difference between TS146Si and TS146Re accurately explained the observed enantiomeric ratio. The Antilla-Houk's model predicted the wrong stereochemistry but was proposed as the preferred pathway to the minor product.

Later, Antilla, Houk and coworkers reinvestigated the mechanism of the enantioselective allylation and propargylation reactions catalyzed by $(R)$-TRIP-PA $(R)-136$ at different DFT levels of theory (B3LYP and B3LYP-D3/6-31G*). The results were coincident with those obtained by Goodman et al. and provided further insight to rationalize the experimental enantioselectivity. ${ }^{60}$

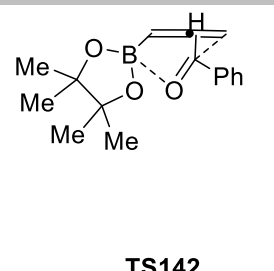

Background reaction $\Delta \Delta \mathrm{G}^{\ddagger}=+5.5$

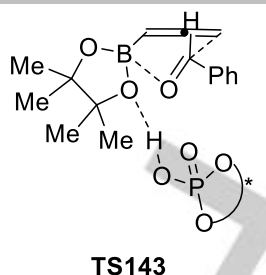

TS143

Antilla-Houk's model $\Delta \Delta \mathrm{G}^{\ddagger}=+5.0$ Wrong stereochemistry

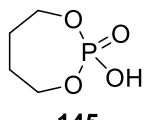

145
$\mathrm{Me}_{\mathrm{Me}}$

TS144

Reddy's model $\Delta \Delta \mathrm{G}^{\ddagger}=+9.0$ (using 150)

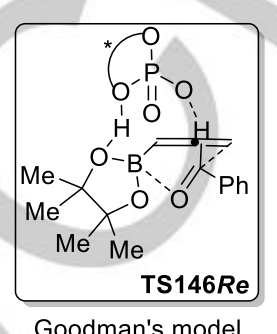

Goodman's model $\Delta \Delta \mathrm{G}^{\ddagger}=0.0$
Right stereochemistry

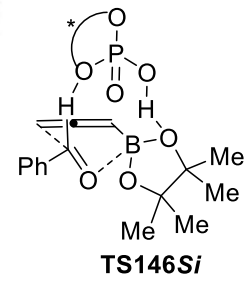

Goodman's model $\Delta \Delta \mathrm{G}^{\ddagger}=2.1$

(2.7 using full catalyst)
Scheme 28. Theoretical study of the propargylboration of aldehydes catalyzed by $(R)-136$. Energies in $\mathrm{kcal} \mathrm{mol}^{-1}$ using biphenol model unless otherwise noted.

Malkov et al. used chiral Brønsted acid catalyst $(R)$-TRIPPA $(R)-\mathbf{1 3 6}$ to obtain Z-homoallylic alcohols $\mathbf{1 4 8}$ through kinetic resolution of racemic $\alpha$-substituted pinacol allylboronates $( \pm)$ 147 (Scheme 29). ${ }^{61}$ DFT calculations were performed to optimize the $E / Z$ ratios by the in silico design of the boronate moiety.<smiles>CC=[R]=C(CC)CCCCC</smiles>

134

$$
\text { (1) }
$$

$( \pm)-147$

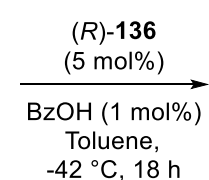

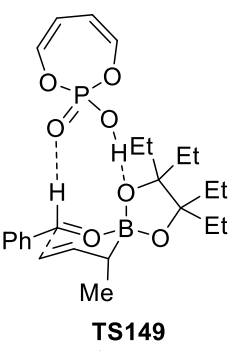<smiles>[R]/C=C\C([R])O</smiles>

148

14 examples Yields: $70-97 \%$ ee: $85-99 \%$ $Z / E>25: 1$

Scheme 29. Enantioselective synthesis of Z-homoallylic alcohols catalyzed by $(R)-136$. Energies in $\mathrm{kcal} \mathrm{mol}^{-1}$.

They predicted that the more selective synthon was the tetraethylethylene glycol boronate 147 and found that the preferred TS (TS149) corresponded to the Goodman's model, ${ }^{55}$ which was ca. $2 \mathrm{kcal} \mathrm{mol}^{-1}$ lower that the TS leading to the $E$ isomer. This result was experimentally validated affording a 97:3 $Z / E$ ratio. The methodology was applied to obtain 14 homoallylic alcohol derivatives with yields in the range $70-97 \%$ and ee of 85 $99 \%$ with a remarkable preference for the $Z$ isomer $(E / Z>25: 1)$. 


\section{Summary}

Asymmetric organocatalytic $\mathrm{C}-\mathrm{C}$ bond forming reactions with organoboron compounds constitute a prominent area of organic chemistry and this topic has been growing exponentially in the last years both in number of publications and in impact. While the development of methodologies with boronic acid derivatives has been extensively advanced, attempts to elucidate the reaction mechanisms are more limited. This review highlights the progress that has been made in this area. Mechanistic studies were carried out theoretically with the aid of DFT calculations and experimentally using different techniques (NMR and ESI-MS, kinetic measurements, etc.). All of these were very useful to identify the most abundant and/or the most reactive species as well as the rate-determining step within the catalytic cycle which, in turn, helped improve the efficiency and the selectivity of the reactions. A deep insight into the numerous factors that affect the reaction mechanisms, such as the coordination with the catalyst, the role of the additives and the properties of the transition structures, is crucial for further development. So, what are the lessons learned so far? Here, we summarize some generalities drawn from mechanistic studies covered in this review:

1. It appears that for BINOL-catalyzed reactions, the most abundant species is the product of a single ligand exchange process between the organoboron compound and the catalyst, which is activated by an internal $\mathrm{H}$-bond (Brønsted acid activation), while the more reactive intermediate is the cyclic boronate formed by double ligand exchange process (Lewis acid activation). Such compound is highly electrophilic due to its distorted geometry which prevents that the oxygens donate electron density into the vacant $p$ orbital on boron, facilitating the tight coordination to the substrate and the subsequent step of addition.

2. When $\alpha$-hydroxyacids are used as catalysts, the reactive species seems to be the five-membered acyloxyborane, activated by the carbonyl and in some cases by an additional intramolecular $\mathrm{H}$-bond. Complexation to the substrate enhances the rate of the addition. However, $\alpha$-hydroxyacids also accelerate reactions in which such step is not possible due to the lack of a heteroatom in the substrate.

3. BINOL-derived phosphoric acids are Brønsted acid catalysts that protonate the pseudoaxial oxygen of the boronate and also experience weaker $\mathrm{H}$-bond interactions (for instance between the phosphoryl oxygen and the formyl hydrogen of aldehydes) that make the system more rigid.

4. While BINOL and $\alpha$-hydroxyacid catalysts require boronic esters that can exchange ligands, BINOLderived phosphoric acids are used with stable boron counterparts.

5. The additive alcohol might serve to suppress the competitive background reaction by generating a less reactive boronic ester derivative and/or to release the organocatalyst from the product of addition.

6. The C-C bond forming addition seems to be the ratedetermining step although the exchange of ligands might compete.
7. In general, the key addition step exhibits a closed sixmembered ring transition structure, in which the boron atom and at least one heteroatom are part of the ring. The geometries vary from sofa-like to chair-like structures, depending on the structure of the substrate and the carbon substituent in the organoboron compound.

8. The enantioselectivity is dictated by a fine combination of effects but generally dominated by steric clashes generated by the substituents of the chiral catalyst.

9. Whilst the first theoretical calculations were initially performed with low cost theory levels using simplified models, thanks to the continuing progress of theory and computation today more accurate results can often be obtained using the complete chemical systems with higher levels of theory. In any case, it should be always kept in mind that theoretical calculation only provide a complementary (though very useful) practice to analyze, rationalize and predict the outcome of experiments.

The mechanism of many asymmetric organocatalytic C-C bond forming reactions have not been theoretically studied yet, such as the asymmetric Petasis reactions or the use of thioureas catalysts or trifluoroborate salts. Those that have not been cited in this minireview are listed in the Supporting Information. Hopefully, this review will contribute to bring further attention and generate new concepts in this fertile area of organic chemistry.

Sebastián O. Simonetti was born in Chabas (Santa Fe, Argentina) and received his $\mathrm{B}$. Sc. degree in Chemistry in 2011 from the National University of Rosario (UNR), and his PhD in 2016, as a Doctoral Fellow of the National Research Council (CONICET) at the Institute of Chemistry Rosario (IQUIR, CONICET-UNR) under the supervision of

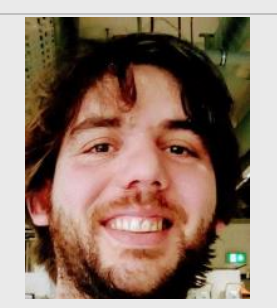

Dr. Kaufman. In 2016, he joined Dr. Pellegrinet's group and focused on the asymmetric organocatalytic reactions with organoboranes. In 2017, he was awarded a Fellowship of the Alexander von Humboldt Foundation at the Max Planck Institute of Colloids and Interfaces in Germany under the supervision of Dr. Pfrengle to synthetize fragments of oligosaccharides belonging to the plant cell wall, returning to IQUIR in 2018. His research interests include the total synthesis of bioactive heterocyclic natural products and the study of reactions of glycosides with interesting biological activity.

Silvina C. Pellegrinet studied Chemistry at the National University of Rosario (B. Sc. 1995 and PhD 1999). During her PhD she worked on total synthesis under the supervision of Dr. Spanevello. She then conducted postdoctoral research on the study of different cyclization reactions under the

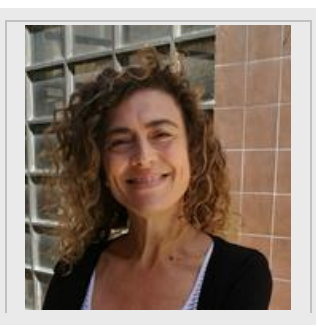
supervision of Dr. Goodman in the Department of Chemistry of the University of Cambridge (UK). In 2001, she returned to Argentina as a Postdoctoral Fellow with Dr. Rúveda. Since 2002, she has been working on the study, design and development of organoborane 
reactions. Silvina has been an Assistant Professor since 2011. Her research interests include different aspects of organic chemistry such as asymmetric synthesis, organocatalysis, pericyclic reactions, organoboron compounds and computational chemistry.

\section{Acknowledgements}

We thank CONICET, Universidad Nacional de Rosario and ANPCYT for financial support. SOS acknowledges CONICET for a postdoctoral fellowship and $\mathrm{AvH}$ foundation for support.

Keywords: Organoboron compounds - Asymmetric synthesis • Organocatalysis • DFT studies $\cdot$ reaction mechanisms 
WILEY-VCH

\section{MINIREVIEW}

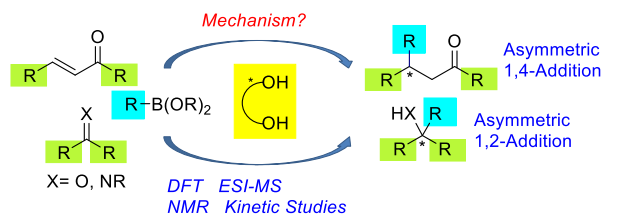

Asymmetric organocatalytic additions can be carried out with different organoboron compounds to give products with very good yields and enantiomeric ratios. Herein, we describe the mechanisms that have been proposed based on theoretical and experimental studies for asymmetric organocatalytic $\mathrm{C}-\mathrm{C}$ bond forming reactions with organoboron compounds.

\section{Organocatalysis - Organoboranes}

Simonetti, S. O., Pellegrinet S. C.*

Page No. - Page No.

Asymmetric Organocatalytic C-C Bond Forming Reactions with Organoboranes: A Mechanistic Survey 
References:

1 a) D. G. Hall, Boronic acids: preparation, applications in organic synthesis and medicine, John Wiley \& Sons, 2006; b) M. Yamashita in Synthesis and Application of Organoboron Compounds, Springer International Publishing, Switzerland, 2015.

2 a) G. Berionni, B. Maji, P. Knochel, H. Mayr, Chem. Sci. 2012, 3, 878; b) J. W. B. Fyfe, A. J. B. Watson, Chem. 2017, 3, 31.

3 a) R. Jana, T. P. Pathak, M. S. Sigman, Chem. Rev. 2011, 111, 1417; b) H. C. Brown, Tetrahedron 1961, 12, 117; c) H. C. Brown, G. Zweifel, J. Am. Chem. Soc. 1961, 83, 486.

4 (a) D. Hnyk, M. L. McKee, Boron: The Fifth Element, Vol. 20, Springer, 2015; (b) L. Xu, S. Zhang, P. Li, Chem. Soc. Rev. 2015, 44, 8848-8858.

5 a) A. Suzuki, Angew. Chem. Int. Ed. 2011, 50, 6722; b) D. Liu, E. Canales, E. J. Corey, J. Am. Chem. Soc. 2007, 129, 1498; c) A. J. J. Lennox, G. C. Lloyd-Jones, Chem. Soc. Rev. 2014, 43, 412.

6 a) F. Jäkle, in Synthesis and Application of Organoboron Compounds (Eds.: E. Fernández, A. Whiting), Springer International Publishing, Cham, 2015, pp. 297-325; b) P. Chen, R. A. Lalancette, F. Jäkle, J. Am. Chem. Soc. 2011, 133, 8802.

7 a) C. Sun, B. Potter, J. P. Morken, J. Am. Chem. Soc. 2014, 136, 6534; b) C. Kleeberg, L. Dang, Z. Lin, T. B. Marder, Angew. Chem. Int. Ed. 2009, 48, 5350; c) N. A. Isley, F. Gallou, B. H. Lipshutz, J. Am. Chem. Soc. 2013, 135, 17707

8 (a) K. Dubalska, M. Rutkowska, G. Bajger-Nowak, P. Konieczka, J. Namieśnik, Critical Reviews in Analytical Chemistry 2013, 43, 35-54; (b) M. A. Champ, P. F. Seligman, Organotin: environmental fate and effects, Springer Science \& Business Media, 2012.

9 Hiyama, T. (2007). Organosilicon Compounds in Cross-Coupling Reactions. In Metal-Catalyzed Cross-Coupling Reactions (eds F. Diederich and P. J. Stang).

10 a) Z. He, A. Zajdlik, A. K. Yudin, Acc. Chem. Res. 2014, 47, 1029.

11 a) A. J. Lennox, Organotrifluoroborate preparation, coupling and hydrolysis, Springer Science \& Business Media, 2013; b) G. A. Molander, J. Org. Chem. 2015, 80, 7837; c) G. A. Molander, N. Ellis, Acc. Chem. Res. 2007, 40, 275.

12 a) D. S. Matteson, J. Org. Chem. 2013, 78, 10009; b) J. Cid, H. Gulyas, J. J. Carbo, E. Fernandez, Chem. Soc. Rev. 2012, 41, 3558; c) E. R. Burkhardt, K. Matos, Chem. Rev. 2006, 106, 2617.

13 a) C. Allais, P. Nuhant, W. R. Roush, Org. Lett. 2013, 15, 3922; b) M. P. Krzemiński, M. Ćwiklińska, Tetrahedron Lett. 2011, 52, 3919; c) I. H. Chen, L. Yin, W. Itano, M. Kanai, M. Shibasaki, J. Am. Chem. Soc. 2009, 131, 11664; d) 11664L. Deloux, M. Srebnik, Chem. Rev. 1993, 93, 763.

14 a) B. T. Cho, Chem. Soc. Rev. 2009, 38, 443; b) E. Dimitrijević, M. S. Taylor, ACS Catal. 2013, 3, 945; c) T. Maki, K. Ishihara, H. Yamamoto, Tetrahedron 2007, 63, 8645.

15 a) Y. Uozumi, Y. Matsuura, T. Arakawa, Y. M. A. Yamada, Angew. Chem. Int. Ed. 2009, 48, 2708; b) K. Sawai, R. Tatumi, T. Nakahodo, H. Fujihara, Angew. Chem. 2008, 120, 7023; c) A. Bermejo, A. Ros, R. Fernández, J. M. Lassaletta, J. Am. Chem. Soc. 2008, 130, 15798; d) A. Ros, B. Estepa, A. Bermejo, E. Álvarez, R. Fernández, J. M. Lassaletta, J. Org. Chem. 2012, 77, 4740

16 T. R. Wu, J. M. Chong, J. Am. Chem. Soc. 2005, 127, 3244.

17 a) K. A. Ahrendt, C. J. Borths, D. W. C. MacMillan, J. Am. Chem. Soc. 2000, 122, 4243; b) B. List, R. A. Lerner, C. F. Barbas, J. Am. Chem. Soc. 2000, 122, 2395; c) (c) D. W. C. MacMillan, Nature 2008, 455, 304. 18 a) S. Roscales, A. G. Csaky, Chem. Soc. Rev. 2014, 43, 8215; b) C. Diner, K. J. Szabó, J. Am. Chem. Soc. 2017, 139, 2, c) F. SánchezSancho, A. G. Csákÿ, Synthesis 2016, 48, 2165.

19 a) J. A. May, T. S. Nguyen, T. N. Nguyen, P. Q. Le, P.-A. Chen, R. Vallakati, Synlett 2017, 28, 2093; b) T. N. Nguyen, J. A. May, Tetrahedron Lett. 2017, 58, 1535.

20 T. Nguyen, P.-A. Chen, K. Setthakarn, J. May, Molecules 2018, 23, 2317.

21 (a)N. R. Candeias, F. Montalbano, P. M. S. D. Cal, P. M. P. Gois, Chem. Rev. 2010, 110, 6169; (b) R. Y. Souza, G. A. Bataglion, D. A. C. Ferreira, C. C. Gatto, M. N. Eberlin,B. A. D. Neto, RSC Adv. 2015, 5,
76337; (c) N. R. Candeias, P. M. S. D. Cal, V. André, M. T. Duarte, L. F. Veiros, P. M. P. Gois, Tetrahedron 2010, 66, 2736; (d) T. Roshlom, P. M. P. Gois, R. Franzen, N. R. Candeias, ChemistryOpen, 2015, 4, 39; (e) J. Tao, S. Li, Chin. Chem. Lett. 2010, 28, 41.

22 a) M. Shibasaki, S. Matsunaga, in Privileged Chiral Ligands and Catalysts, Wiley-VCH Verlag GmbH \& Co. KGaA, 2011, pp. 295; b) D. Kampen, C. M. Reisinger, B. List, in Asymmetric Organocatalysis (Ed.: B. List), Springer Berlin Heidelberg, Berlin, Heidelberg, 2009, pp. 1-37; c) G. Li, F. Liu, M. Wu, ARKIVOC, 2015, vi, 140.

23 S. C. Pellegrinet, J. M. Goodman, J. Am. Chem. Soc. 2006, 128, 3116. 24 T. R. Wu, J. M. Chong, J. Am. Chem. Soc. 2007, 129, 4908.

25 R. S. Paton, J. M. Goodman, S. C. Pellegrinet, J. Org. Chem. 2008 73, 5078 .

26 B. J. Lundy, S. Jansone-Popova, J. A. May, Org. Lett. 2011, 13, 4958. 27 a) I. S. Young, P. S. Baran, Nat. Chem. 2009, 1, 193; b) P. S. Baran T. J. Maimone, J. M. Richter, Nature 2007, 446, 404.

28 P. Q. Le, T. S. Nguyen, J. A. May, Org. Lett. 2012, 14, 6104.

29 T. S. Nguyen, M. S. Yang, J. A. May, Tetrahedron Lett. 2015, 56, 3337.

30 L. Caruana, M. Fochi, L. Bernardi, Molecules 2015, 20, 11733; (b) M. S. Singh, A. Nagaraju, N. Anand, S. Chowdhury, RSC Adv. 2014, 4, 55924 .

31 Y. Luan, S. E. Schaus, J. Am. Chem. Soc., 2012, 134, 19965.

32 (a) W. B. Eyton, W. D. Ollis, I. O. Sutherland, O. R. Gottlieb, M. Taveira Magalhâes, L. M. Jackman, Tetrahedron 1965, 21, 2683; (b) J. T. Cook, W. D. Ollis, I. O. Sutherland, O. R. Gottlieb, Phytochemistry 1978, 17, 1419; (c) S.-C. Chan, Y.-S. Chang, J.-P. Wang, S.-C. Chen, S.-C. Kuo, Planta Med 1998, 64, 153

33 M. N. Grayson, J. M. Goodman, J. Org. Chem. 2015, 80, 2056.

34 M. Sugiura, M. Tokudomi, M. Nakajima, Chem. Comm. 2010, 46, 7799.

35 M. Sugiura, R. Kinoshita, M. Nakajima, Org. Lett. 2014, 16, 5172.

37 N. Grimblat, M. Sugiura, S. C. Pellegrinet, J. Org. Chem. 2014, 79 6754.

38 (a) K. Furuta, Y. Miwa, K. Iwanaga, H. Yamamoto, J. Am. Chem. Soc. 1988, 110, 6254; (b) K. Furuta, S. Shimizu, Y. Miwa, H. Yamamoto, J. Org. Chem. 1989, 54, 1481.

39 N. Grimblat, A. M. Sarotti, P. L. Pisano, S. C. Pellegrinet, New. J. Chem. 2016, 40, 1966.

40 H.-X. Huo, J. R. Duvall, M.-Y. Huang, R. Hong, Org. Chem. Front. 2014, 1, 303.

41 S. Lou, P. N. Moquist, S. E. Schaus, J. Am. Chem. Soc. 2006, 128, 12660.

42 S. Lou, P. N. Moquist, S. E. Schaus, J. Am. Chem. Soc. 2007, 129, 15398.

43 (a) Woollard, S. M., Kanmogne, G. D., Drug design, development and therapy, 2015, 9, 5547-54468; (b) M. R. López-Huertas, L. JiménezTormo, N. Madrid-Elena, C. Gutiérrez, S. Rodríguez-Mora, M. Coiras, J. Alcamí, S. Moreno, Sci. Rep. 2017, 7, 2385.

44 D. S. Barnett, P. N. Moquist, S. E. Schaus, Angew. Chem. Int. Ed. 2009, 48, 8679

45 R. S. Paton, J. M. Goodman, S. C. Pellegrinet, Org. Lett. 2009, 11, 37.

46 J. A. Bishop, S. Lou, S. E. Schaus, Angew. Chem. Int.Ed. 2009, 48, 4337.

47 C. H. Senanayake, D. A. Pflum, D. Krishnamurthy, Z. Han, S. A. Wald, Tetrahedron Lett. 2002, 43, 923

48 T. R. Wu, L. Shen, J. M. Chong, Organic Letters 2004, 6, 2701-

49 D. S. Barnett, S. E. Schaus, Org. Lett. 2011, 13, 4020.

50 M. N. Grayson, J. M. Goodman, J. Org. Chem. 2013, 78, 8796.

51 R. Alam, T. Vollgraff, L. Eriksson, K. J. Szabó, J. Am Chem. Soc. 2015, 137, 11262

52 R. Alam, C. Diner, S. Jonker, L. Eriksson, K. J. Szabó, Angew. Chem. Int. Ed. 2016, 55, 14417.

53 G. Huang, C. Diner, K. J. Szabó, F. Himo, Org. Lett. 2017, 19, 5904. 
54 P. Jain, J. C. Antilla, J. Am. Chem. Soc. 2010, 132, 11884.

55 M. N. Grayson, S. C. Pellegrinet, J. M. Goodman, J. Am. Chem. Soc. 2012, 134, 2716.

56 In 2016, an experimental and theoretical study of the asymmetric allyl(propargyl)boration of ortho-alkynyl benzaldehydes catalyzed by $(R)$ TRIP-PA was reported. E. Rodríguez, M. N. Grayson, A. Asensio, P. Barrio, K. N. Houk, S. Fustero, ACS Catalysis, 2016, 6, 2506.

57 L. R. Reddy, Org. Lett. 2012, 14, 1142.

58 P. Jain, H. Wang, K. N. Houk, J. C. Antilla, Angew. Chem. Int. Ed. 2012, 51, 1391.

59 M. N. Grayson, J. M. Goodman, J. Am. Chem. Soc. 2013, 135, 6142. 60 H. Wang, P. Jain, J. C. Antilla, K. N. Houk, J. Org. Chem. 2013, 78, 1208

61 C. A. Incerti-Pradillos, M. A. Kabeshov, A. V. Malkov, Angew. Chem. Int. Ed. 2013, 52, 5338 